\title{
A Review of Wind Tunnel Based Virtual Flight Testing Techniques for Evaluation of Flight Control Systems
}

\author{
Min Huang and Zhong-wei Wang \\ Science and Technology on Scramjet Laboratory, National University of Defense Technology, Changsha, Hunan 410073, China \\ Correspondence should be addressed to Min Huang; hm653925451@icloud.com
}

Received 8 June 2015; Revised 30 August 2015; Accepted 18 October 2015

Academic Editor: Paolo Tortora

Copyright ( 2015 M. Huang and Z.-w. Wang. This is an open access article distributed under the Creative Commons Attribution License, which permits unrestricted use, distribution, and reproduction in any medium, provided the original work is properly cited.

Wind tunnel based Virtual Flight Testing (VFT) is a dynamic wind tunnel test for evaluating flight control systems (FCS) proposed in recent decades. It integrates aerodynamics, flight dynamics, and FCS as a whole and is a more realistic and reliable method for FCS evaluation than traditional ground evaluation methods, such as Hardware-in-the-Loop Simulation (HILS). With FCS evaluated by VFT before flight test, the risk of flight test will be further reduced. In this paper, the background, progress, and prospects of VFT are systematically summarized. Specifically, the differences among VFT, traditional dynamic wind tunnel methods, and traditional FCS evaluation methods are introduced in order to address the advantages of evaluating FCS with VFT. Secondly, the progress of VFT is reviewed in detail. Then, the test system and key technologies of VFT for FCS evaluation are analyzed. Lastly, the prospects of VFT for evaluating FCS are described.

\section{Introduction}

(1) What Is Virtual Flight Testing? A broad definition of Virtual Flight Testing (VFT) is given here. In a wind tunnel, some kind of aircraft model, full-scaled or reduced scaled, is supported by a model support system, which can insure the free attitude motions of the model and limits the translational motions of the model. The model support rig can be a solid strut system with bearings, a wire suspension system with bearings, or even a potential magnetic suspension system. The model directly or indirectly responds to the model's actuator and freely pitches, yaws, and rolls or performs other maneuvers. The actuator is controlled by the aircraft controller in real time. The indirect response means that after the actuator moves, the model motion is driven by a forcing mechanism with predicted attitude, which can be computed by real-time measuring of the aerodynamic moment. In this way, an equivalent free motion in response to the model controller can be provided. For example, in Figure 1, the missile model freely pitches and rolls on bearings, while yaws are equivalently forced by the top mechanism with realtime predicted yaw position. With the VFT defined here, attitude stability and control test can be performed. In such a test, free rotation motions should be comparable to that of real flights. To simulate real flight with VFT realistically, some similarity criterions have to be satisfied, such as flow similarity and motion similarity. In this test, attitude response and aerodynamic forces and moments can be measured and fed back to the controller. If kinematical equations are added into the FCS loop of VFT, 6 DOFs motions of aircraft can be simulated (such as VFT shown in Figure 2 or Figure 11). With such a VFT system, guidance and navigation test can be performed. Brief introduction towards these VFT tests will be introduced in Sections 2 and 3.

VFT does not replace flight test or other ground tests but attempts to provide a more realistic ground test method to evaluate unsteady or transient aerodynamic characteristics and flight control system performances. It is considered as a bridge between ground testing and flight testing to reduce flight test risks [1]. Some features of VFT are similar to Hardware-in-the-Loop Simulation (HILS), except that VFT allows the aircraft to perform at simulated flight conditions in wind tunnel. Some literatures [2-4] treat VFT as one type of HILS; however, in this paper, VFT is distinguished with traditional HILS which is laboratory based, while VFT is wind tunnel based. Therefore, VFT is pulled apart from 


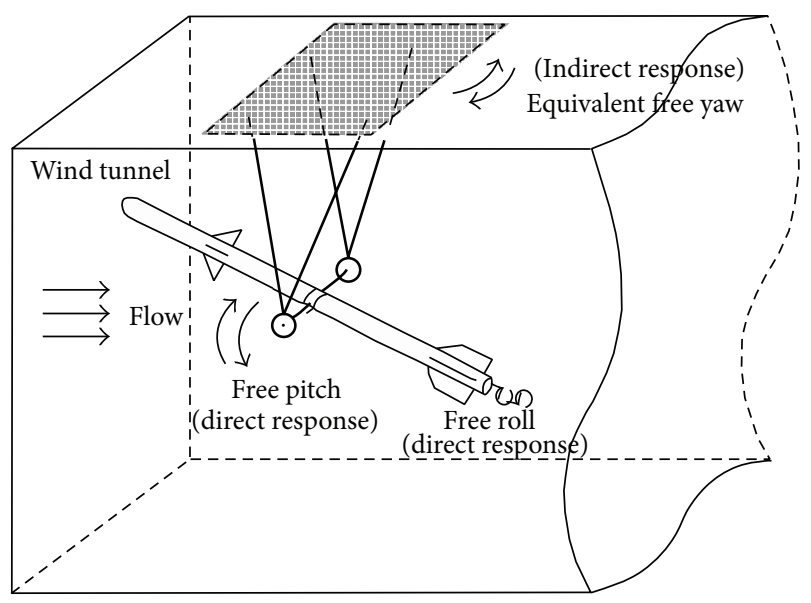

FIGURE 1: Illustration of direct and indirect response in VFT.

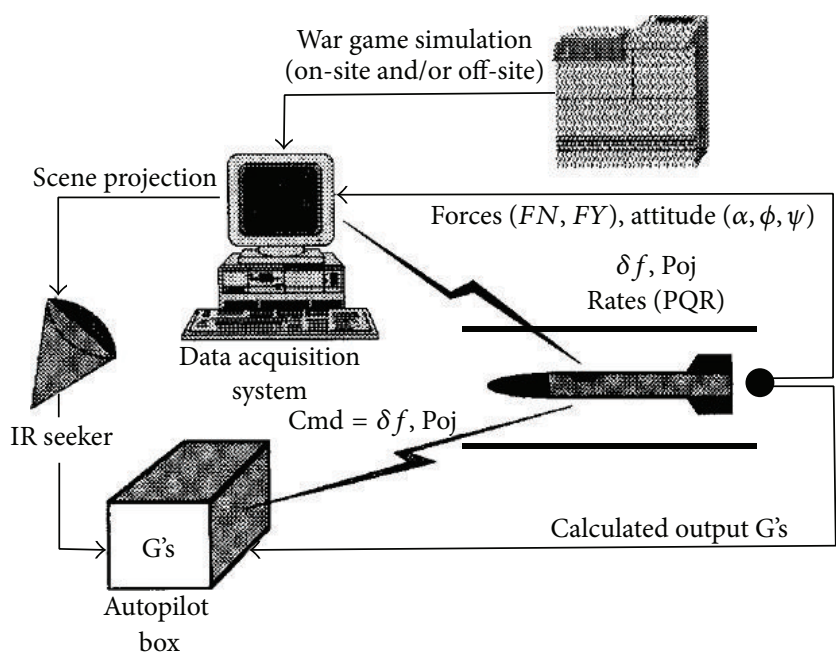

FIGURE 2: VFT scenario for evaluating guidance and control system of missiles [6].

HILS. It is worth mentioning that sometimes "Virtual Flight Testing" is used to describe digital flight simulations, which can be found in [5]. Here, the VFT refers particularly to a kind of flight simulation test conducted in wind tunnels and is quite different from the above digital flight simulations which are performed on computers.

An example of a full VFT scenario involving a high speed intercept missile performing maneuvers required for a direct hit-to-kill mission is presented in [6]. It is used to evaluate the guidance and control system of missiles before flight test, as shown in Figure 2. Specifically, the IR seeker and autopilot box are located in separate facilities (located either on or off the Arnold Engineering Development Center (AEDC)), while the test model is mounted on a spherical gas bearing installed in a wind tunnel. The spherical gas bearing supports the model with a near frictionless pitch, yaw, and roll pivot. A threat scenario determined by a war game facility is projected on the focal plane array of an IR seeker by the AEDC Direct Write Scene Generator (DWSG) using the synthetic scene generation model (SSGM). The IR seeker thus communicates

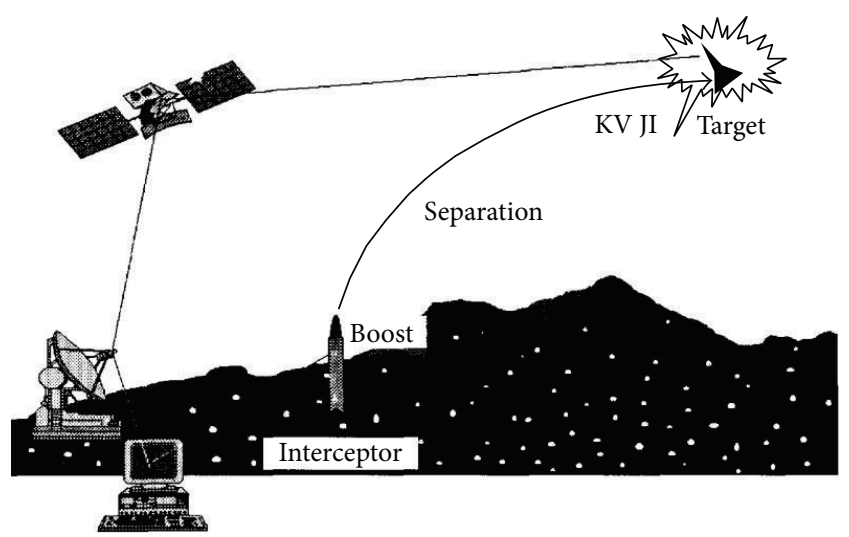

FIGURE 3: Flight test of intercept vehicle [6].

the tracking image coordinates to the autopilot. The autopilot commands are transferred via telemetry to the model in the tunnel to change its attitude (pitch, roll, and yaw) by either a jet control system or aerodynamic control surfaces. Once the model actuators respond to the input commands, the model's new attitudes (pitch, yaw, and roll) and positions are transmitted back to the DWSG to update the information of IR seeker with a new spatially transformed scene. The closed-loop process continues until the target is intercepted or missed or the missile fails to complete its mission (see Figure 3).

As a dynamic wind tunnel test, VFT is quite different from traditional dynamic wind tunnel tests. To further understand the concept of VFT, major differences between VFT and traditional dynamic wind tunnel tests are given. According to [7], traditional dynamic wind tunnel tests for flight dynamics research can be categorized as captive wind tunnel test, wind tunnel single degree-of-freedom (1-DOF) test, and wind tunnel free-flying test.

Forced oscillation wind tunnel test [8-14] and rotary balance wind tunnel test [15-18] constitute the captive category. They are used to measure the damping and rotary derivatives. The distinct feature of captive wind tunnel test is that the test model is driven by a model support mechanism. Therefore, the model motion is not the free motion mode like real flight. For example, in [12], an UAV aircraft is mounted on a sting in the NASA Langley Research Center 12-Foot Low Speed Tunnel (as shown in Figure 4) and undergoes forced roll oscillation driven by the sting to obtain roll damping derivatives.

Wind tunnel 1-DOF test includes free-to-pitch (or freeto-yaw) wind tunnel test [19-22] and free-to-roll wind tunnel test [23-25]. They let the test model oscillate freely on a support apparatus under an initial condition and are usually used to identify free motion modes and dynamic stability derivatives. Wind tunnel 1-DOF test allows rapid assessment of unsteady aerodynamics effects on the motion of model without the complexity of a free-flying test or VFT. The NASA Langley 16-ft Transonic Tunnel (TT) free-to-roll (FTR) apparatus [24] is taken as an example here. A 1/15thscale F-35 aircraft model is mounted on the FTR apparatus 
TABLE 1: Comparisons between VFT and traditional dynamic wind tunnel tests.

\begin{tabular}{lcccccc}
\hline $\begin{array}{l}\text { Dynamic wind } \\
\text { tunnel tests }\end{array}$ & Captive & $\begin{array}{c}\text { Wind tunnel } \\
\text { 1-DOF }\end{array}$ & $\begin{array}{c}\text { Low speed } \\
\text { free-flight }\end{array}$ & $\begin{array}{c}\text { High speed } \\
\text { free-flight }\end{array}$ & Free spin/tumble/fall & FFT \\
\hline $\begin{array}{l}\text { Form of model } \\
\text { motion }\end{array}$ & FCM & FEM & FEM & FEM & FEM & FEM \\
\hline Form of FCS & $\begin{array}{c}\text { Without } \\
\text { control }\end{array}$ & $\begin{array}{c}\text { Without } \\
\text { control }\end{array}$ & $\begin{array}{c}\text { Closed-loop } \\
\text { control }\end{array}$ & $\begin{array}{c}\text { Without } \\
\text { control }\end{array}$ & $\begin{array}{c}\text { Without or open-loop } \\
\text { control (if applicable) }\end{array}$ & $\begin{array}{c}\text { guidance/closed-loop } \\
\text { control }\end{array}$ \\
\hline $\begin{array}{l}\text { Applications for } \\
\text { flight dynamics }\end{array}$ & SDM, CLD & SDM, CLD & $\begin{array}{c}\text { SDM, CLD, } \\
\text { FQE, and } \\
\text { CLEE }\end{array}$ & SDM, CLD & S/T RPE, TMDM & $\begin{array}{c}\text { SDM, CLD, FQE, } \\
\text { CLEE, S/T RPE, and } \\
\text { FPE }\end{array}$ \\
\hline
\end{tabular}

FCM: forced motion; FEM: free motion; SDM: stability derivatives measurement; CLD: control law design; FQE: flying qualities evaluation; CLEE: control law effects evaluation; S/T RPE: spin/tumble recovery performances evaluation; TPDM: trajectories prediction of dropped model; and FPE: flight performances evaluation.

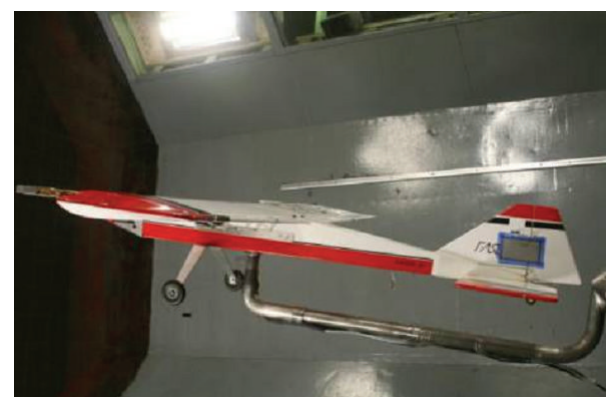

FIGURE 4: An UAV aircraft mounted on a forced oscillation rig [12].

and rolls freely on the rig (see Figure 5). During the test, the roll-angle time history is measured, which is then used to estimate roll damping derivative based on the equation of FTR motion.

Free spin tests are often conducted in a vertical spin tunnel (VST) (a typical VST from NASA is shown in Figure 6). In a VST, varying buoyancy can be produced by adjusting the speed of upward airstream in real time to counterbalance the model gravity, so that the model can float in the teat section as long as possible. In the free spin tests, if model's flight control system is added, model control surfaces would be actuated by using premium off-the-shelf remote control (R/C) hobby gear (i.e., transmitter, receiver, servos, batteries, etc.) in the form of open-loop control to perform spin recovery strategies [7].

Free tumble tests are usually used to research the tumble motion and its recovery performances of high speed aircraft (such as the prober or reentry capsule). Free tumble tests are similar to free spin tests, except that the duration of free tumble tests is usually quite short. The reason is that a tumbling model creates net lift and will traverse the test section rapidly. When longer test time is desired, a "free-topitch" rig can be used [7]. Free fall tests are used to predict the attitude motions and flight trajectories of dropped test articles. The dropped model performs free falling motions just like the real situations. Free fall tests can also be conducted in a VST (as Figure 7 shows).

There are mainly two kinds of wind tunnel free-flight tests: (1) low speed free-flight tests [26-34] with power system, which can provide enough thrust to counterbalance aerodynamic drag so that the center of gravity of the test model will be kept in an axis line when the model attitude is changing (an example of such tests is shown in Figure 8), and (2) high speed (subsonic/transonic/supersonic/hypersonic) free-flight tests [35-39], which do not have power systems and will result in a free falling motion of the test model without control. Low speed free-flight tests with power can be used to investigate flying qualities and control law effects up to a maximum trim angle of attack or until loss of control occurs [7], while high speed free-flights are mainly used to identify stability derivatives with measured attitudes and trajectories.

The differences between traditional dynamic wind tunnel tests and VFT are shown in Table 1. From Table 1, we can summarize the following four obvious differences:

(1) Compared to captive wind tunnel test, the motion form of VFT is free motion, while the motion form of captive wind tunnel tests is forced motion.

(2) VFT is quite similar to wind tunnel 1-DOF. Their common features are reflected in that their model supports both adopt a contact-type mechanical rig, and their motion forms of model are both free motions. The differences are that VFT is not just limited to 1-DOF, and the flight control system (FCS) is added in VFT.

(3) Compared to wind tunnel free-flying tests (including low speed free-flight, high speed free-flight, and free spin/tumble/fall), though the model motion form of VFT is also free motion, the model of VFT is constrained by a contact-type mechanical rig. Such a rig will inevitably bring some aerodynamic interference to the test article, while the models of wind tunnel free-flying tests are unconstrained, which can get rid of the aerodynamic interference of model support.

(4) As for the applications for flight dynamic researches, VFT can not only be applied for some traditional purposes, such as stability derivatives measuring, control law design and evaluation, and spin/tumble recovery performances evaluation (see Section 2.3), 


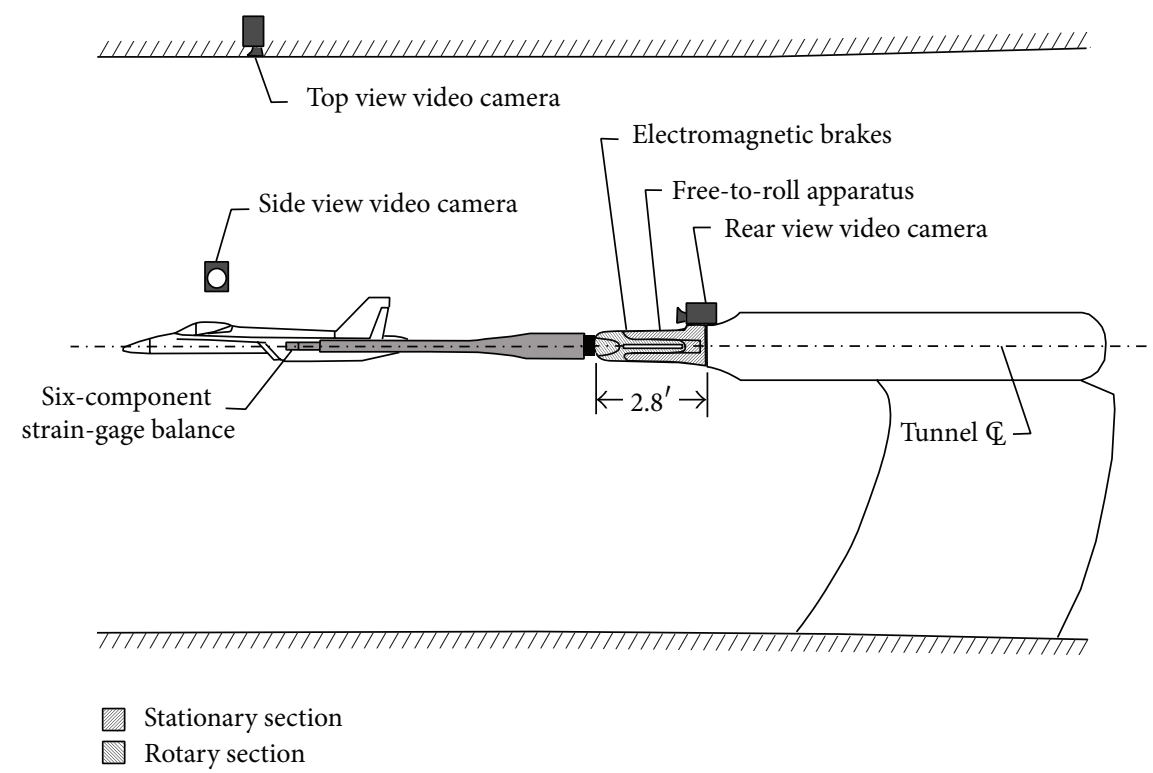

FIgURE 5: Sketch of the NASA Langley 16-ft TT FTR apparatus [24].

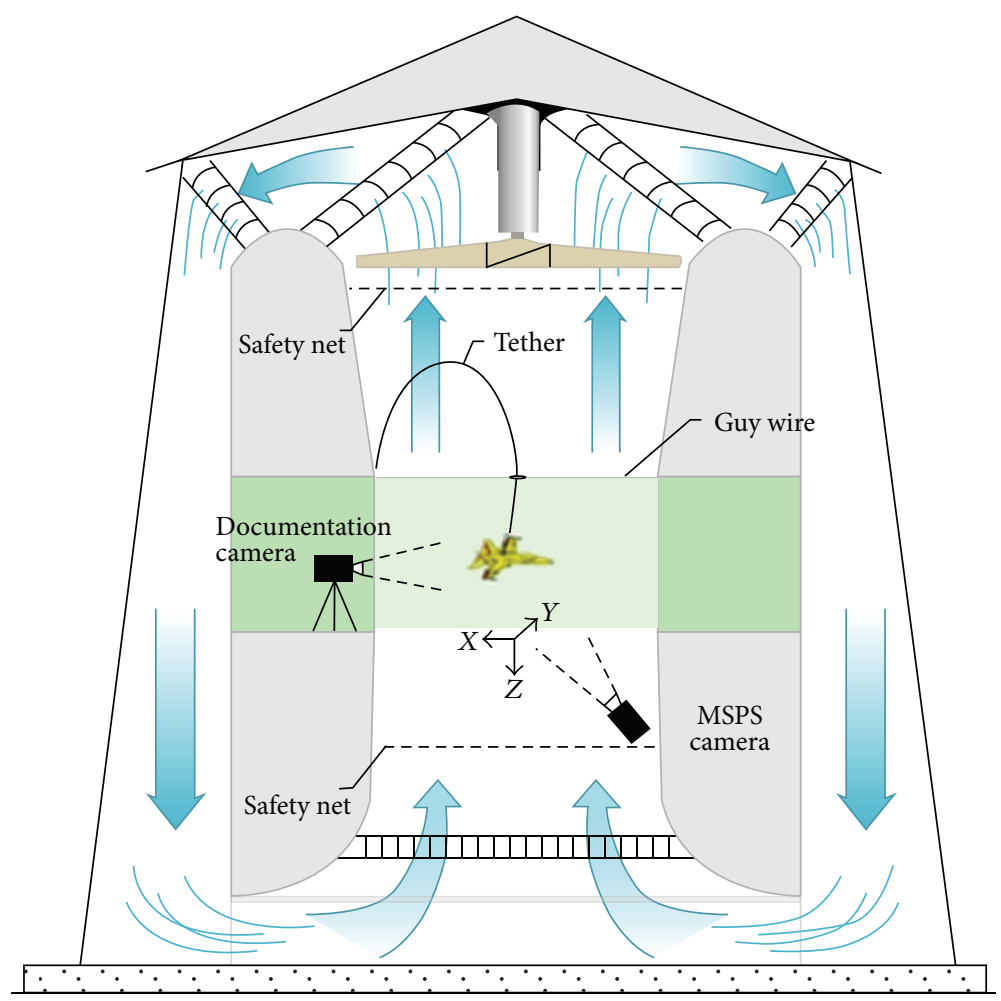

FIgURE 6: A cutaway drawing of the VST in NASA [7].

but also be applied for some new purposes, such as flight performances evaluation due to the capability of simulating the aircraft trajectory in VFT.

(2) Why Is VFT Used to Evaluate Flight Control Systems? As shown in Section 1(1), VFT can be used for lots of purposes. However, in this paper, FCS evaluation is the purpose we are concerned about. Thus, the background of VFT will be given from the point of FCS evaluation. To illustrate the background of VFT sufficiently, two sides are, respectively, introduced: the advantages of VFT towards traditional dynamic wind tunnel tests in FCS evaluation and the advantages of VFT towards traditional FCS evaluation methods. Then, a short summarization of VFT background 


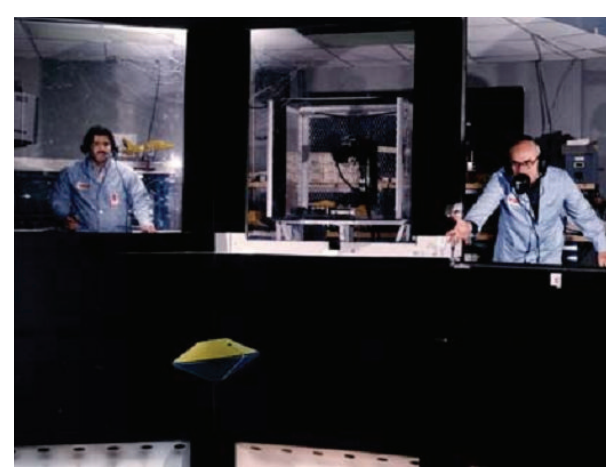

FIGURE 7: Return capsule model performing free fall motions in a VST [7].

is given, which will help make the necessity and importance of VFT more clearly understood.

(a) The Advantages of VFT towards Traditional Dynamic Wind Tunnel Tests in FCS Evaluation. Among the traditional wind tunnel tests in Table 1, only the low speed wind tunnel freeflight tests with power and free spin/tumble tests have the FCS and can be used to evaluate partial performances of FCS, while other dynamic tests are mainly applied to measure stability derivatives and design flight control law.

As low speed wind tunnel free-flight tests with power and free spin/tumble tests can all be used to evaluate performances of FCS like VFT, their differences are as follows:

(1) The form of FCS: the FCS forms of free spin/tumble tests are open-loop control and the FCS forms of low speed wind tunnel free-flight tests with power are closed-loop control, while the FCS forms of VFT can be closed-loop guidance and closed-loop control at most.

(2) The motion simulated: free spin/tumble tests can only be used to simulate spin or tumble and wind tunnel free-flight tests with power can only be used to simulate attitude motions at low speed, while VFT can be used to simulate both attitude motions and real flight trajectories at various speeds (low, subsonic, transonic, supersonic, and even hypersonic speed).

(3) The performances that can be evaluated: free spin/tumble tests can only be used to evaluate spin or tumble recovery strategies and low speed wind tunnel free-flight tests with power can be used to evaluate attitude control performances and flying qualities at low speed, while VFT can be used to evaluate guidance and control performances, flight performances, and flying qualities at various speeds.

From the above comparisons, traditional dynamic wind tunnel tests cannot simulate real 6-degree-of-freedom flight and high speed free-flight with closed-loop control and therefore cannot evaluate guidance and control system and closedloop control performances at high speed, while VFT can supply this gap. Due to the wider simulation and evaluation capabilities of VFT compared to traditional dynamic wind tunnel tests, VFT greatly broadens the capabilities of wind tunnel tests, especially in FCS evaluation.

(b) The Advantages of VFT towards Traditional FCS Evaluation Methods. In general, the process of developing a FCS is a combination of design activities and evaluation activities. Once a FCS is designed, the designed FCS has to be evaluated to decide whether the flight performances and flying qualities of an aircraft under the action of FCS can be satisfied. If the flight performances and flying qualities cannot be satisfied, the FCS should be redesigned until it meets the above requirements. Up to now, lots of methods have been developed to evaluate the FCS. These methods mainly include numerical simulation, Software-in-the-Loop Simulation (SILS), Hardware-in-the-Loop Simulation (HILS), Pilotin-the-Loop Simulation (PILS), and flight test [42-73]. They are of different fidelity and are used in different stages of FCS development, as illustrated in Figure 9. Brief introductions towards these methods are as follows.

When guidance law and control law of FCS are developed, numerical simulation [42-52] is used to evaluate FCS with aircraft and its FCS all modeled. This method is easy to be realized and can be performed in hundreds of times in short time, so as to evaluate FCS in various possible flight conditions. However, its fidelity is the lowest among all methods. In 1950s, people began to use simulation method to develop missiles, which greatly reduced the number of flight tests. For instance, it takes more than 1000 times of flight tests to develop Nike missile with flight test only. But after numerical simulation is added for developing Police Dog Missile, only 92 missiles are launched. Since then, numerical simulation is used for evaluating almost any kind of aircraft FCS.

When kinds of software of FCS are developed, SILS can be performed. This method is used to evaluate the FCS with software added into the simulation loop. Some examples of SILS for evaluating FCS can be found in $[53,54]$.

HILS follows when kinds of FCS hardware are developed. By adding real hardware into the simulation loop as many as possible (such as flight control computer, actuator, or sensors), the performances of FCS with hardware in the simulation loop can be evaluated. The reason why HILS is adopted is that the simulated hardware models are hard to exactly describe the real characteristics of hardware, especially the nonlinear features. In recent decades, a multitude of HILS laboratories are built throughout the world. One most complicated is the Advanced Simulation Center (ASC) in Redstone base. In 1970s, HILS systems are based on the analog-digital (or hybrid) computers, such as the patriot hybrid HILS system [55], the semiactive missile hybrid HILS system [56], the hybrid HILS system in RDEC [57], and the TR-I rocket hybrid HILS system [58]. In 1980s, alldigital computers emerge, which makes the hybrid computers gradually replaced by full-digital computers in HILS systems. With full-digital computers, the accuracy of HILS is greatly improved. Since then, a large number of all-digital HILS systems are built for developing FCS of missiles [59-64], rockets [65-68], Unmanned Aerial Vehicles (UAVs) [69], 


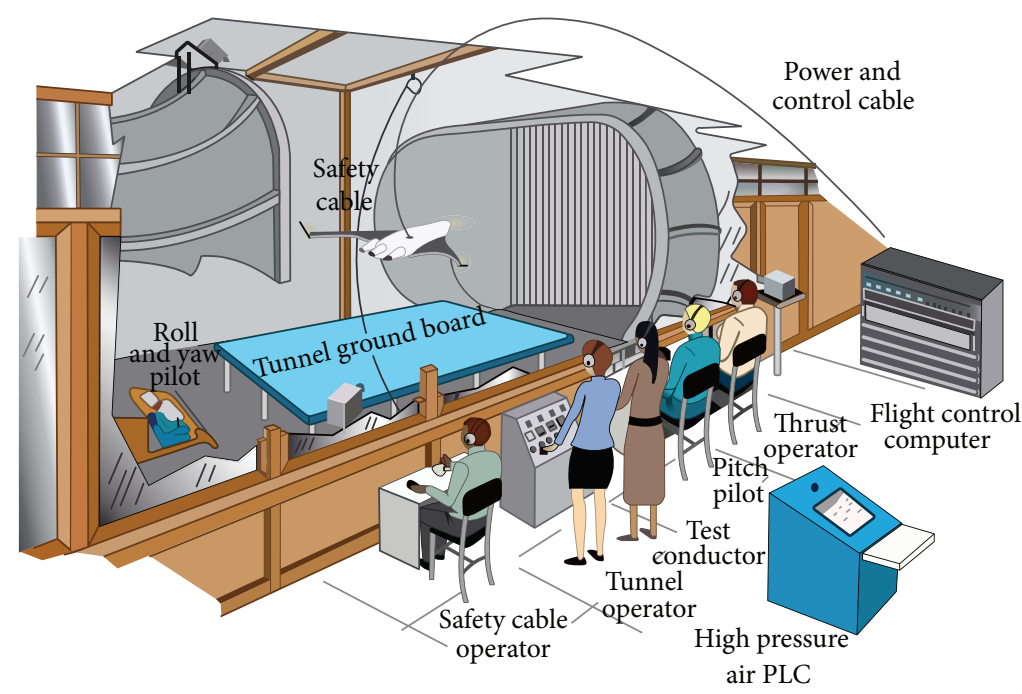

FIGURE 8: Low speed free-flight test setup with power system in the LFST [7].

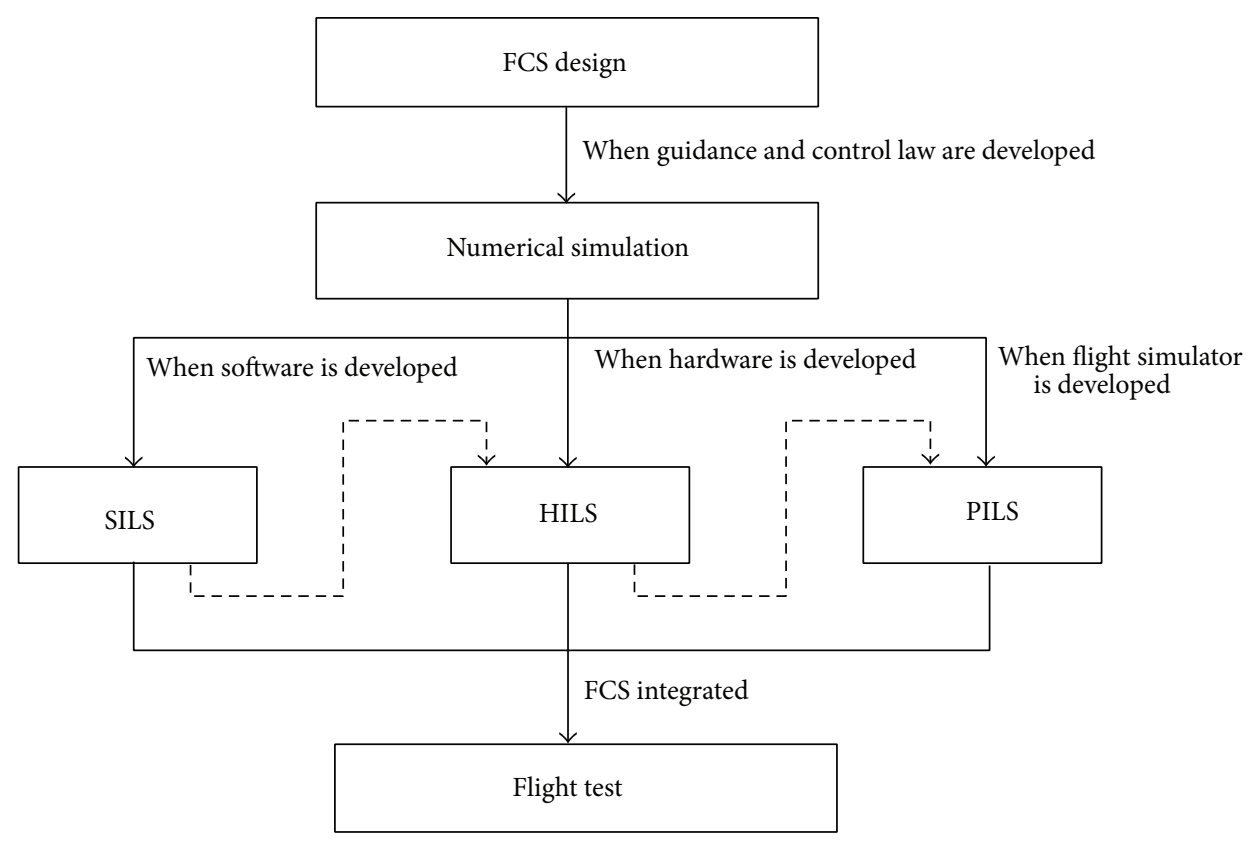

FIGURE 9: Methods for evaluating FCS in different development phase.

spacecraft [70], and airplanes [71]. Introduction of the HILS evaluation process can be found in [42, 48, 49, 71-73].

With flight simulator added into the simulation loop, PILS can be performed. It is used to evaluate the influences of pilot manipulation on the FCS. The FCS software and hardware of this method can be all-modeled but also can be all real depending on the development phase. Obviously, it is specially used to evaluate the FCS of manned aircraft, as can be seen in [74-76].

After being evaluated by SILS, HILS, or PILS, guidance and control law, software, and hardware will be integrated for flight test. In flight tests, the integrated FCS is evaluated in real flight conditions. The fidelity of flight test is the highest. Only through flight test, complete performances of FCS can be evaluated and exposed. Since the beginning of the twentieth century, when Wright brothers achieved the controlled flight of gliders [77], flight test has been the indispensible and final method for FCS evaluation [42-44, 72, 73, 76, 78-82].

Differences between VFT and traditional FCS evaluation methods are listed in Table 2. As Table 2 shows, HILS is the most realistic among the traditional ground evaluation methods. Loads on control surfaces must be loaded by a load simulator physically, whose loading moments come from a look-up table created by wind tunnel hinge moment tests [83]. The attitude and translational motions of aircraft must be simulated by building kinematic equations. In order to provide aerodynamic forces and moments for the kinematic equations of aircraft, aerodynamic models (such as look-up 
TABLE 2: Comparisons between VFT and traditional evaluation methods.

\begin{tabular}{|c|c|c|c|c|c|c|}
\hline Methods for evaluating FCS & Numerical simulation & SILS & HILS & PILS & VFT & Flight test \\
\hline Software & M & $\mathrm{R}$ & $\mathrm{R}$ & $\mathrm{M}$ or $\mathrm{R}$ & $\mathrm{R}$ & $\mathrm{R}$ \\
\hline Hardware & M & $\mathrm{M}$ or $\mathrm{R}$ & $\mathrm{R}$ & $\mathrm{M}$ or $\mathrm{R}$ & $\mathrm{R}$ & $\mathrm{R}$ \\
\hline Loading moments on control surfaces & M & M & M & M & RAS & $\mathrm{R}$ \\
\hline Aerodynamic forces and moments & M & M & M & M & RAS & $\mathrm{R}$ \\
\hline Attitude motions & M & M & M & M & RAS & $\mathrm{R}$ \\
\hline Translational motions & M & M & M & M & M & $\mathrm{R}$ \\
\hline
\end{tabular}

M: mathematical model; R: real; and RAS: real but airflow is simulated; the "RAS" means that the loading moments on control surfaces/aerodynamic forces and moments/attitude motions are real like that of flight test, except that the airflow in wind tunnel is simulated and cannot get that real like the airflow in the air.

tables) have to be created by wind tunnel aerodynamic tests or CFD [84]. While in VFT, loading moments on control surfaces, aerodynamic forces and moments, attitude motions are all real by putting the aircraft model in the simulated wind tunnel airflow and changing the model attitudes in real time under the action of FCS. Therefore, on the one hand, VFT is closer to flight test and can provide a more realistic ground test environment for FCS evaluation than traditional ground evaluation methods. On the other hand, though the FCS and flight environment of flight test are all real, it is of high risk. Once the flight test fails, the aircraft tested is unrecoverable, which will result in large loss and lengthened development cycle. According to the above analyses, through applying the most realistic ground evaluation method, VFT, to evaluate FCS, the reliability of FCS for flight test can be increased and the risk of flight test can be further decreased.

(c) Summarization of Background. The reasons why VFT is used for evaluation of flight control systems are summarized here. The deficiencies of traditional dynamic wind tunnel tests and traditional FCS evaluation methods are listed below:

(1) The deficiencies of traditional dynamic wind tunnel tests in FCS evaluation: among traditional dynamic wind tunnel tests, there is still lack of a kind of dynamic wind tunnel test which can simulate real 6degree-of-freedom flight and high speed free-flight with closed-loop control. Therefore, with traditional dynamic wind tunnel tests, guidance and control system and closed-loop control performances at high speed cannot be evaluated. In this way, a kind of dynamic wind tunnel test like VFT is needed.

(2) The deficiencies of traditional FCS evaluation methods: the loading moments on control surfaces, aerodynamic forces and moments, and attitude motions of an aircraft have to be modeled mathematically; flight test is of high risk and cost. Therefore, it is necessary to increase the reliability of FCS before flight test, so as to reduce the risk of flight test. In this way, a more realistic ground evaluating method for FCS like VFT is needed.

With VFT, the deficiencies of traditional dynamic wind tunnel tests in FCS evaluation and traditional FCS evaluation methods can be effectively gaped. On the one hand, VFT can be used to evaluate not only the closed-loop control performances at high speed but also the guidance and control system. On the other hand, the loading moments on control surfaces, aerodynamic forces and moments, and attitude motions of an aircraft in VFT are all real. This makes the VFT more realistic than the traditional FCS ground evaluation methods. Thus, the reliability and technology maturity of FCS for flight test can be further increased, and the potential risks of flight tests can be decreased more than ever before.

Based on the above analyses, we can get to know that VFT is quite useful and necessary for the development of FCS in the long run. We hope that the key technologies of VFT for evaluation of FCS can be broken through as soon as possible. However, we have to make sure the vehicle rotations in VFT are similar to real flights. This is not that easy and demands high cost. Therefore, to accelerate the development of VFT techniques, more manpower and material resources are needed. A survey of VFT techniques for evaluation of FCS will help draw more attention of relevant researchers and departments.

This paper is structured as follows. The concept of VFT and the background of VFT for evaluating FCS are introduced in Section 1. The research progress of VFT is reviewed in Section 2. The test system and key technologies of VFT for FCS evaluation are analyzed in Section 3. The prospect of VFT for FCS evaluation is addressed in Section 4. Finally, the conclusions are presented in Section 5.

\section{Progress of VFT}

Due to the obvious advantages of VFT among ground tests, many countries are actively developing VFT techniques. According to the aforementioned broad definition of VFT, the published literatures show that the main countries developing VFT techniques are the United States, the United Kingdom, Russia, India, and China. Their development histories are introduced, respectively, below.

2.1. Progress of VFT in the United States. Since the concept of VFT was first proposed in 1995 [1], the Arnold Engineering Development Center (AEDC) and Physical Sciences Inc. (PSI) have been researching VFT techniques till today. Their primary purpose is to evaluate the guidance and control system of missiles with VFT prior to live flight tests so as to reduce the flight test risk. 


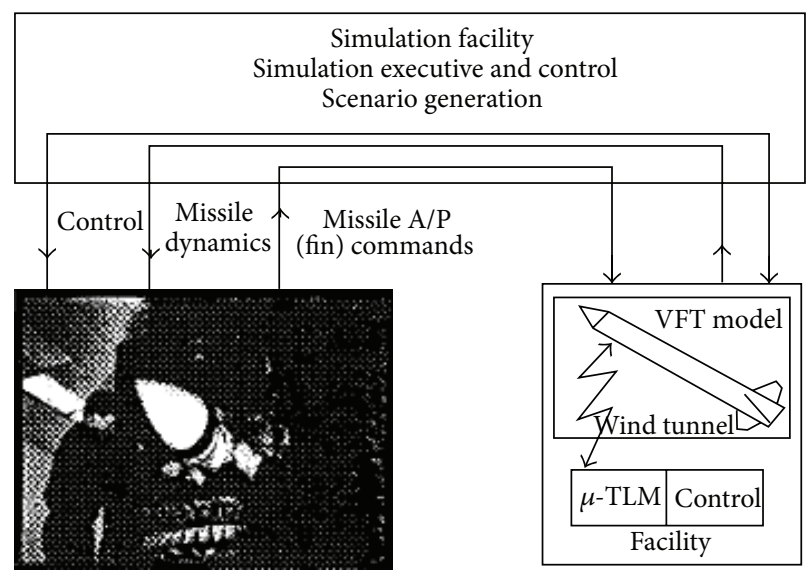

Existing HIL facility
Wind tunnel facility and VFT model

FIgURE 10: For the wind tunnel free-flying test, the aircraft model is remotely controlled or uncontrolled. It flies unconstrainedly in the tunnel test section, which can avoid the interference of model support rigs. The only aerodynamic interference comes from the safety cable (if added). Free-flying test methods include free-flight [26-39], free spin [40], free tumble [41], and free fall [7]. A VFT architecture proposed by Standard Missile Company [85].

In 1997, Schoenfeld and Priolo [85] from the Standard Missile Company introduced VFT architecture depicted in Figure 10. It integrates the wind tunnel with 6-DOF simulation. Existing Hardware-in-the-Loop (HIL) facility sends out missile autopilot commands. Wind tunnel facility ensures that the VFT model receives the commands, changes the attitude in real time, and feeds back missile dynamics. The Computer-in-the-Loop (CIL) facility runs actual flight software. It processes and transmits data and controls the whole test.

In 1997, Magill et al. [86] from PSI gave a more visualized depiction to the highest level of VFT fidelity described by Ratliff and Marquart (see Figure 11). A missile is mounted on a 3-DOF gas bearing so that the missile will be restrained from translation. The missile is outfitted with control jets, which drive the missile to rotate about three axes freely. The missile attitude and aerodynamic and control-induced loads on the missile can be measured at the gas bearing. With the above measured information, the computer controlling the experiment can then be used to calculate the translational motions. Thus, a complete model flight trajectory can be constructed. From the flight trajectory, an artificial scene can be generated and projected onto the focal plane array of an IR targeting system. In this way, a virtual flight environment evaluating guidance system can be constructed as if in real flight.

The earliest work on VFT techniques was funded by the Air Force Office of Scientific Research (AFOSR). Early in that effort, it was recognized that when a flight vehicle is constrained by a model support system, its measured response will not be identical to actual free-flight response $[87,88]$. Therefore, a team of experts representing multiple disciplines, including representatives from the Air Force Research Laboratory (AFRL), the Sverdrup/Technical Engineering

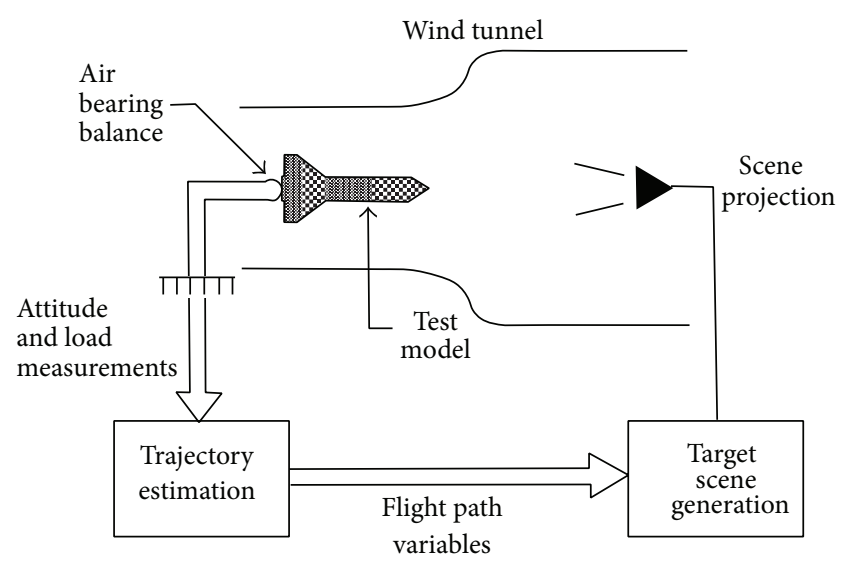

Figure 11: A possible VFT arrangement [86].

Acquisition Support (TEAS) group at Eglin AFB, the Naval Air Warfare Center Weapons Division (NAWCWD) at China Lake, and the AEDC, was assembled, in order to (1) develop a VFT simulation method by which the free-flight response could be derived from wind tunnel measurements and (2) identify the constituent component technologies necessary for the development of a VFT capability, namely, a model support system, a high-frequency measurement system, a fast two-way telemetry capability, and a process control interface to integrate the free-flight response simulation into the closed-loop control system. The final conclusion of the AFOSR project was that the VFT concept seemed viable and should be pursued [89].

In 2000, Gebert et al. [90] proposed several VFT simulation methods. The ability of these methods to reproduce free-flight was evaluated. A preliminary assessment of these methods was conducted using 3-DOF models employing linear aerodynamics and assuming an ideal support system. By comparing the response of free-flight simulation and VFT simulation, a VFT simulation method using reconstructed pitch/yaw rate gyro signals was supposed to be suitable for reproducing free-flight. With this method, the VFT environment was capable of reproducing the free-flight behavior within acceptable differences, but due to the lack of translation in the VFT, some discrepancies were noted, particularly for open-loop control airframe.

In 2002, AEDC and China Lake engineers [91] conducted demonstration tests of VFT at the High Velocity Airflow System at the Weapon Survivability Lab at Naval Air Warfare Center to prove that VFT is in fact a viable concept. A test support frame was positioned in front of the HiVAS so that the BOA missile, suspended in the frame by an eightwire suspension system, could be centered in the airflow as shown in Figure 12. The BOA missile, which is a proven airframe that has flown before, is a fin-controlled, reducedspan variant of the AIM-9M Sidewinder air-to-air missile. It is configured with a flight autopilot, telemetry (TM) section, a gas grain generator to power the fins, thermal batteries to power the TM section, rate sensors, Guidance and Control Section (GCS), and a Class B rocket motor. The eight-wire suspension system allows the missile to freely 


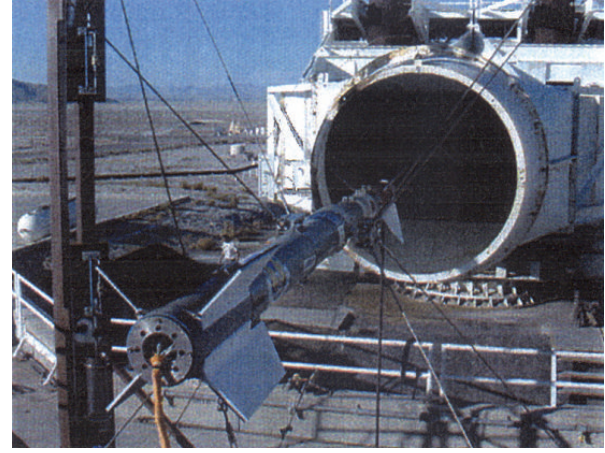

Figure 12: HiVAS/BOA test configuration [91].

pitch and roll but restricts the yaw motion. The flight autopilot computer was preprogrammed to execute a series of time-dependent pitch rate commands to simulate flight maneuvers. The demonstration results show that the dynamic response of the aerodynamically unstable missile is similar to that experienced in flight both when released prior to autopilot initialization and when the autopilot was engaged prior to release, producing pitch, yaw, and roll rates similar to those observed in actual flight tests. This means that a wire suspension system is a viable means of supporting a test article for a VFT test and that a missile can operate under its own closed-loop control while being constrained by its support system. Through the HiVAS demonstration test, the feasibility of the VFT concept was preliminarily proven.

Later, PSI [92] designed and built a small-scale six-wire system which contained a three-axis ball-bearing pivot to provide enough amplitude of roll, pitch, and yaw motions (see Figure 13) and demonstrated this system in a $40 \mathrm{in}$. wind tunnel at Georgia Institute of Technology. As this support system incorporates yaw bearings and would produce substantial aerodynamic interference for the model, PSI [93] designed a new suspension system (see Figure 14). With this system, yaw motion is produced by a set of hydraulic modules to pull or relax the cables (see Figure 15). To provide an equivalent free yaw motion and damp unsteady oscillations in the cables, a hydraulic control system was designed. The collar assembly (see Figure 16), including pairs of roll and pitch bearings, can provide free motion in roll and pitch axes. The collar also includes an internal strain-gage half-balance that will be able to measure axial, normal, and side forces, as well as yawing moment. Given model inertia about the yaw axis, the hydraulic actuators will impart yaw acceleration to the model in proportion to the measured yawing moment. This will provide an apparent yaw degree of freedom. Pitch angle and roll angle can be measured by pitch encoder and roll encoder, respectively.

In 2005, Magill et al. [94] described a repetitive-learning algorithm for the active yaw control. In 2009, the tests of the above VFT system with this learning controller were introduced [95]. The tests, conducted at Ma from 0.4 to 0.6, demonstrate the functionality of the VFT system using a series of missile pitch and yaw maneuvers. The results show the following: (1) when the missile is programmed for steady

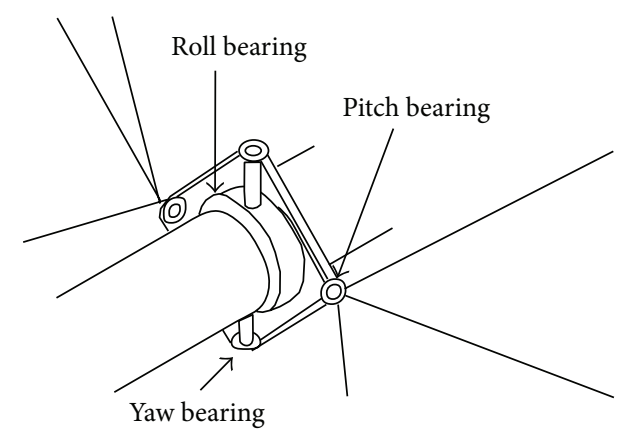

FIGURE 13: Proposed six-wire system configuration [92].

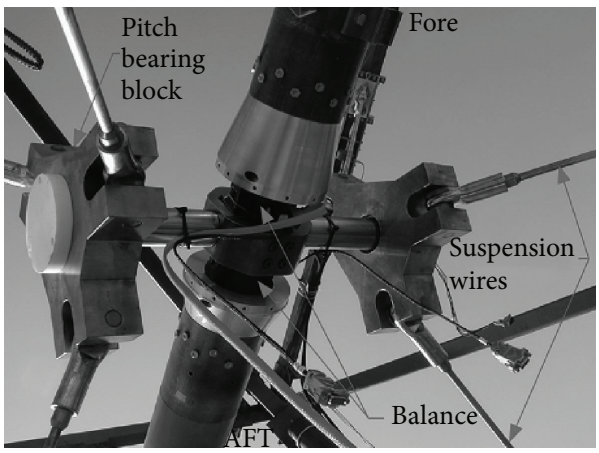

FIGURE 14: Improved six-wire suspension system [95].

level flight, the controller is attempting to hold a zero-pitch rate; but when the missile is disturbed from a pitch angle of $\Psi=0$, the controller will stop the pitch motion (restore $\dot{\Psi}$ to zero) but will not return the missile to $\Psi=0$; (2) the learning controller is shown to learn an " $\mathrm{s}$ " maneuver in the yaw plane; (3) the roll locking observed in flight tests was reproduced, which is a behavior wherein the missile rolls freely at low angles of attack and stops rolling suddenly when the angle of attack increases. This shows that key missile stability characteristics can be recreated in a VFT.

2.2. Progress of VFT in the United Kingdom. Research departments of VFT techniques in UK include the Cranfield University, the University of Bristol, and the University of Cambridge. Their primary purposes are investigating the dynamic stability and control characteristics of aircraft, identifying stability derivatives, modeling nonlinear aerodynamic characteristics, and designing and evaluating flight control law. Brief introductions are given as follows.

Since 1980, Department of Aerospace Sciences in Cranfield University has been researching VFT techniques, for the purpose of investigating the dynamic stability and control characteristics of small UAVs [96-99]. Four-degree-offreedom support rig for the 1/12 scale Hawk model was built in a low speed open-section wind tunnel (see Figure 17) [100]. The degrees of freedom permitted by the rig are shown in Figure 18. The range of motion that the rig permits is \pm 30 degrees of rotation in roll and pitch, 360 degrees in yaw, and a translation of approximately $0.75 \mathrm{~m}$ in the vertical 


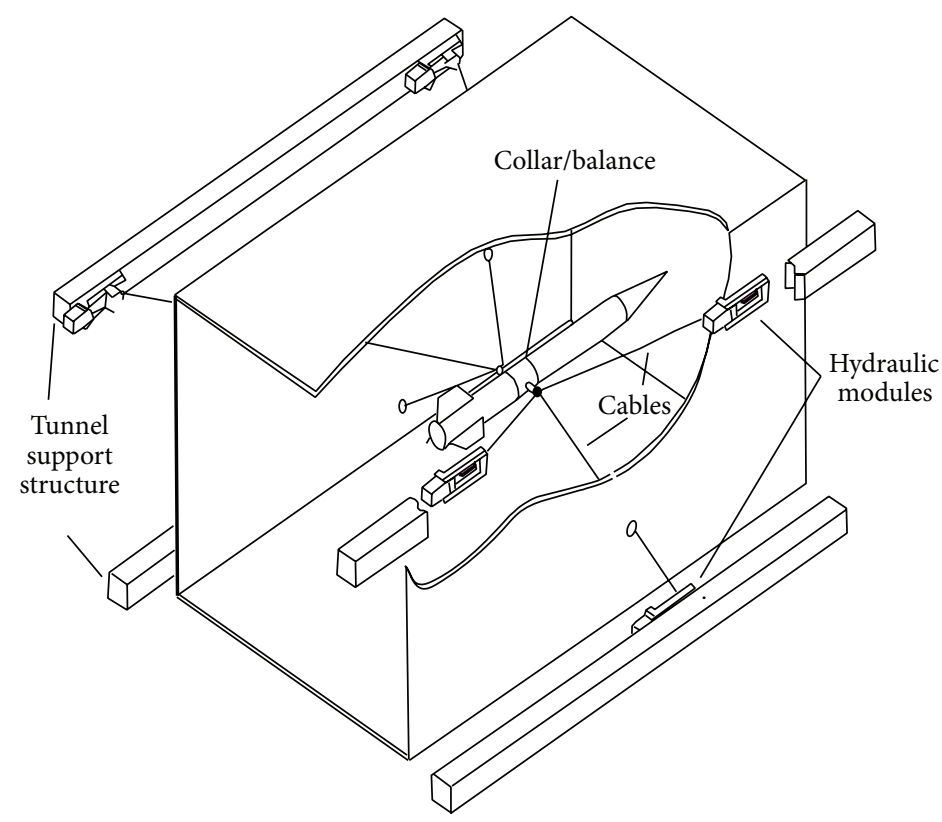

FIGURE 15: Hydraulic modules for actuating the missile model to yaw [93].

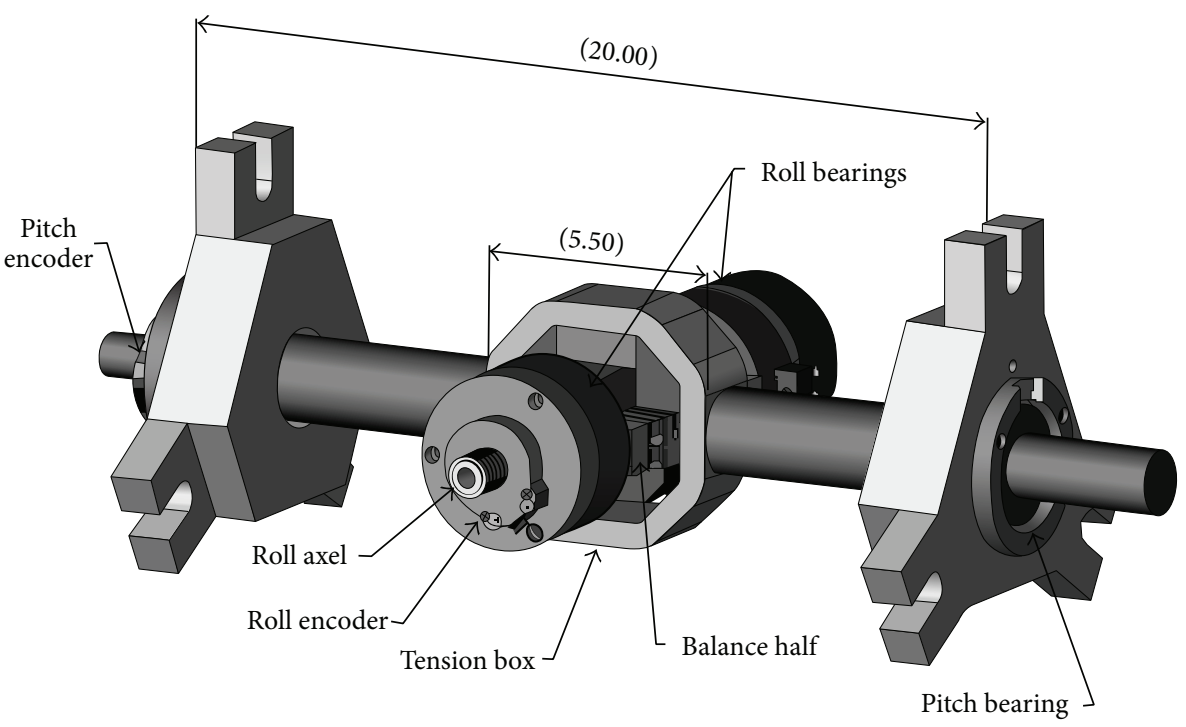

FIGURE 16: Collar assembly supporting missile fore-and-aft sections and providing free pitch and roll [95].

axis. The model control system includes an electronic control unit as a small, self-contained, and transportable console; potentiometers sensing the angular motion in each axis; and small precision servoactuators driving the deflections of the tailplane or foreplane, the ailerons, and rudders. In 1987, Cook [100] used the 4-DOF rig to evaluate the aircraft short-period-mode dynamics by measuring the frequencies, damping ratios, and time constants of the stability modes of the Hawk model and to estimate stability derivatives with Kalman Filtering method. In 2008, Carnduff et al. [101, 102] used microelectromechanical systems (MEMS) sensor to measure the model's angular motion replacing the previous potentiometers. With the improved test facility, parameter estimation to obtain reliable flight dynamics information about the full-size aircraft was performed in the frequency domain using the equation error and output error methods.

University of Bristol began to research VFT techniques in 2000, for the purpose of providing a low cost control law development method. One-DOF [103, 104], 2-DOF [105], 3-DOF [106], and 5-DOF [107, 108] dynamic wind tunnel rig were built. The 5-DOF rig is shown in Figure 19, which allows model pitch, model yaw, model roll, rig pitch (model heave), and rig yaw (model sway), as illustrated in Figure 20. In order to acquire data and control the test model, a dSPACE DS1103 real-time operating system was used, using Matlab/Simulink and Real-Time Workshop for rapid 


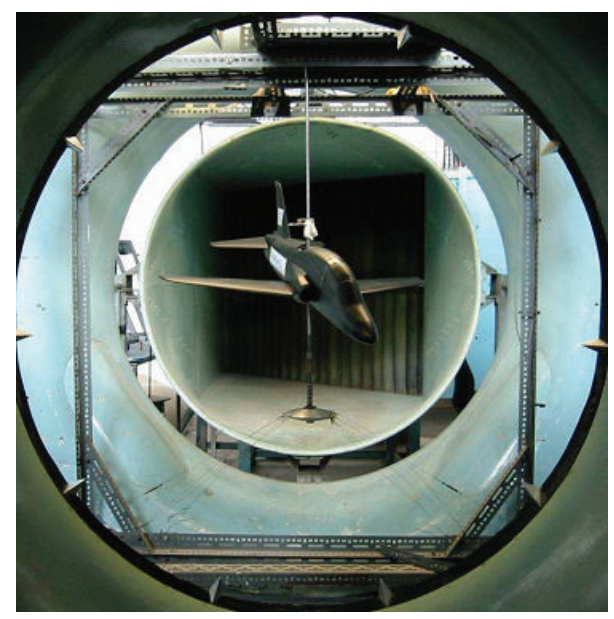

FIGURE 17: Four-degree-of-freedom support rig in a low speed opensection wind tunnel [101].

control system prototyping. Attitude sensors are precision carbon-film potentiometers for measuring angular positions (accurate to $\pm 0.05^{\circ}$ ) and solid-state rate gyros for measuring angular velocities $\left( \pm 0.25^{\circ} / \mathrm{s}\right.$ accuracy). The model actuators are radio-controlled. With the above test systems, researched contents include developing the mathematical model of the rig system and controllers for the rig [103, 109], modeling nonlinear aerodynamic characteristics such as limit cycles $[104,110]$, and estimating stability derivatives [106-108].

In 1999, Papageorgiou and Glover [111] from the University of Cambridge built a 2-DOF dynamic wind tunnel rig allowing free pitch and yaw of the wind tunnel model (see Figure 21), for the purpose of developing two-degree-offreedom controller for the High Incidence Research Model (HIRM) so as to achieve robust tracking of the pilot's commands. The HIRM wind tunnel model includes two actuators for each DOF. The differential tailplane and thrusters at the top of the vertical rod provide rolling power, the nose suction, and air jets at the rear of the plane provide yawing power. The pitch and yaw attitudes of the aircraft are measured by two high-resolution optical encoders. In 2002, wind tunnel tests of the active controlled HIRM model were performed, and the robust tracking performance of the designed 2-DOF controller was evaluated [112].

2.3. Progress of VFT in Russia. The VFT in Russia is used to investigate the free spin modes and spin recovery strategies of fighters. In 2002, Sohi et al. [113] from the Siberian Aeronautical Research Institute (SibNIA) in Russia introduced a 3 -DOF rig in the T-203 horizontal wind tunnel at SibNIA. The 3 -DOF rig provides the model with free rotation in pitch, yaw, and the airflow direction (see Figure 22). The model control system includes spin control computers outside the wind tunnel, radio-controlled actuators, transducers measuring the model motion parameters, and a one-component strain-gage balance measuring the drag force of the rotating model. With the rig, spin modes were measured, and spin characteristics of the Su-26 sport aircraft were estimated. In 2004, several spin recovery methods for a supersonic aircraft were designed, and the recovery performances of these methods were evaluated [114].

2.4. Progress of VFT in India. The published literatures [115117] show that the VFT in India is mainly used to obtain stability derivatives and estimate stability of aircraft.

In 1987, Balakrishna and Niranjana [115] from the India National Aeronautical Laboratory (NAL) built a single pitch degree-of-freedom rig. This rig allows free rotation of the unstable Standard Dynamic Model ranging from $-10^{\circ}$ to $+30^{\circ}$ (see Figure 23), for the purpose of demonstrating the potentials of the wind tunnel dynamic flying techniques (similar expression of VFT) in evaluating stability and control performances of scaled aerodynamic models. By adjusting the center of gravity (CG) locations of the SDM model until the model got unstable, an active control law was invoked, and the model motion was shown to be stabilized by the active control law. The pitching moment derivatives of the model had been evaluated under both open-loop and closed-loop control conditions using the proven maximum likelihood parameter estimation method. The result and technique had been validated by reasonable comparisons with derivative data from other sources. This study suggests that the dynamic wind tunnel flying experiments route is a simple and viable technique for routine generation of aerodynamic stability data in wind tunnels and is a tool for studying active control laws.

Later in 1993, a 3-DOF rig allowing the free pitch, roll, and yaw motion of a delta winged aircraft model excited by applying inputs to symmetric elevon, differential elevon, and rudder, respectively, was built in NAL (see Figure 24) [116]. The rig was used to achieve a technique called Dynamic Wind Tunnel Simulation (similar expression of VFT). The longitudinal and lateral aerodynamic derivatives of the model were estimated by using parameter estimation technique and were compared with derivatives obtained from conventional testing methods. These methods include static wind tunnel test, free oscillation rig, and forced oscillation rig. With the 3DOF rig, the effectiveness of the model control surfaces was directly estimated, and the neutral point of the model was determined.

In 1997, a novel method of generating comprehensive longitudinal aerodynamic data of aircraft using Dynamic Wind Tunnel Simulation was presented by Rajamurthy in NAL [117]. This method utilizes the motion and force responses of an aircraft model to control surface inputs to determine trim lift characteristics, longitudinal stability derivatives, and neutral point. The new method was demonstrated using a generic delta wing aircraft model on the single pitch degree-of-freedom rig by adding the direct measuring of lift force (see Figure 25). The model pitch attitude and lift force responding to elevon dynamic inputs were measured and used to deduce longitudinal aerodynamic data.

2.5. Progress of VFT in China. The research of VFT techniques in China initiated later in around 2010. The main research units are China Academy of Aerospace Aerodynamics (CAAA) in Beijing and China Aerodynamics 


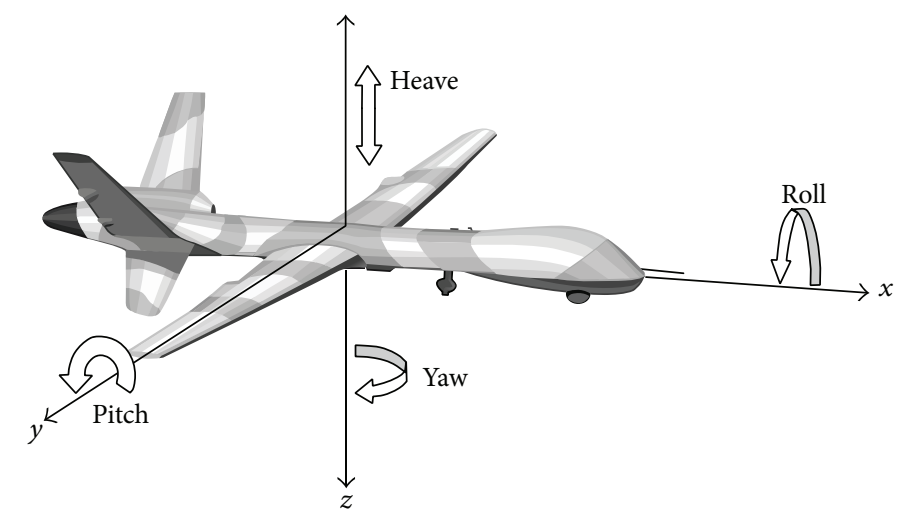

FIGURE 18: The degrees of freedom permitted by the Cranfield 4-DOF rig [101].

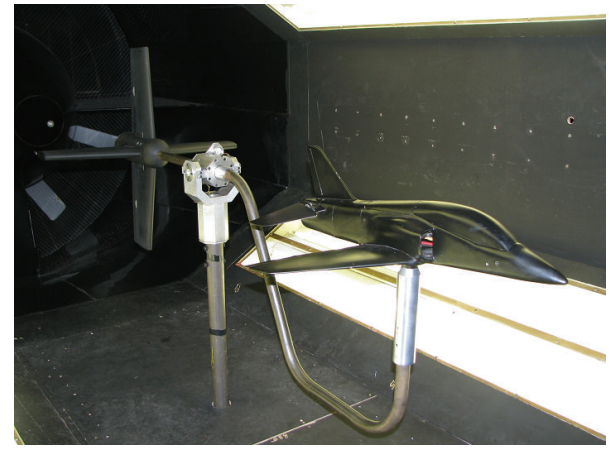

FIGURE 19: The 5-DOF rig mounted in the University of Bristol's $7 \times$ $5 \mathrm{ft}$ closed-section wind tunnel [108].

Research and Development Center (CARDC) in Mianyang of Sichuan province. The purposes of developing VFT techniques in China are mainly to investigate coupling mechanisms between the aerodynamics and flight dynamics and to evaluate flight control laws.

In 2010, Hu and Li [118] from CAAA introduced the first VFT system built in China (see Figure 26), for the purpose of demonstrating the principle and key techniques of VFT system. The techniques of the system they built include combined roll bearings technique, fin actors technique, and cable support system technique. The cable support system is a 2-DOF rig allowing the model to roll and yaw freely with pitch degree of freedom limited. Wind tunnel tests were conducted to test the rolling and yawing responses of the model to the fin deflections in the form of open-loop control without the real-time measuring of attitude angles. Through the wind tunnel tests, the feasibility of VFT was preliminarily verified.

In 2012, the similarity criteria and simulation method of the VFT were researched by Li from High Speed Aeronautics Institution in CARDC $[119,120]$. In order to validate the simulation method, longitudinal flight dynamics with control for a typical missile were numerically simulated, and the verification VFT tests were performed. The verification tests were conducted on the VFT platform in the $2.4 \mathrm{~m}$ transonic wind tunnel of CARDC (see Figure 27). The VFT platform, which is used to explore the coupling mechanisms between the aerodynamics and flight dynamics and to evaluate the flight control law, consists of three subsystems: (1) a 3DOF rig which allows the free pitch and roll of the model and equivalent yaw motion actuated by the top mechanism, (2) VFT control systems including rig control system for actuating the yaw motion and rudder control system, and (3) VFT data acquisition and processing system. With the VFT platform, open-loop control tests of VFT were conducted at $0.6 \mathrm{Ma}$, and the VFT simulation method was preliminarily validated. As the author pointed out, closed-loop control tests of VFT would be performed to fully validate the VFT simulation method.

In 2012, the Low Speed Aeronautics Institution in CARDC [121] designed a scheme of VFT system based on the rapid control prototyping technique (see Figure 28), for the purpose of early evaluating the flight control law before the controller hardware is developed. This VFT system can be used to evaluate flight control laws from different aircraft types and is similar to that developed by the University of Bristol. It includes a scaled aircraft model, a 3-DOF support rig, a VxWorks based RTOS for data acquisition and control, a database computer for recording flight parameters, HP05 IMU for measuring attitude angles, and Volz servos for actuating the aircraft model control surfaces. The VxWorks based RTOS consisted of a host machine and a target machine. The host machine is a master control computer for real-time data acquisition, processing, and display. The target machine is a flight control computer for controlling the aircraft model. The IMU, flight control computer, and servos are put inside the test model. Through wireless Ethernet, the communications among the flight control computer, the database computer, and the master control computer can be achieved.

2.6. Summarization of the VFT Progress. Though the VFT concept was proposed in 1995, the actual research history of VFT could date back to 1980. The status of VFT is summarized in Table 3. The countries, including United Kingdom, Russia, India, and China, use attitude control systems in their VFT systems and have applications towards their respect purposes. Only United States is researching how to evaluate 
TABLE 3: VFT progress of the main countries developing VFT techniques.

\begin{tabular}{|c|c|c|c|c|c|}
\hline Countries & United States & United Kingdom & Russia & India & China \\
\hline Main purposes & $\begin{array}{c}\text { Evaluating } \\
\text { guidance and } \\
\text { control system }\end{array}$ & $\begin{array}{l}\text { Developing and } \\
\text { evaluating FCL }\end{array}$ & Evaluating SRS & $\begin{array}{l}\text { Identifying } \\
\text { aerodynamic } \\
\text { derivatives }\end{array}$ & $\begin{array}{c}\text { Investigating A/FD CM } \\
\text { and developing and } \\
\text { evaluating FCL }\end{array}$ \\
\hline Model supports & Wire suspension & Solid strut & Solid strut & Solid strut & $\begin{array}{l}\text { Wire suspension, solid } \\
\text { strut }\end{array}$ \\
\hline Parameters measured & Attitudes, AFM & Attitudes & Attitudes, drag force & Attitudes, lift force & Attitudes, AFM \\
\hline Form of FCS & GCS & ACS & ACS & ACS & ACS \\
\hline The starting research year & 1995 & 1980 & 2000 & 1987 & 2010 \\
\hline Test progress & $\begin{array}{l}\text { Closed-loop ACT } \\
\text { at subsonic speed } \\
(0.4 \sim 0.6 \mathrm{Ma})\end{array}$ & $\begin{array}{c}\text { Closed-loop ACT } \\
\text { at low speed } \\
(0 \sim 60 \mathrm{~m} / \mathrm{s})\end{array}$ & $\begin{array}{l}\text { Open-loop ACT at } \\
\text { low speed }(15 \mathrm{~m} / \mathrm{s})\end{array}$ & $\begin{array}{l}\text { Closed-loop ACT at } \\
\text { low speed }(32 \mathrm{~m} / \mathrm{s})\end{array}$ & $\begin{array}{l}\text { Closed-loop ACT at } \\
\text { transonic speed }(0.9 \mathrm{Ma})\end{array}$ \\
\hline Research status & $\begin{array}{l}\text { Under research, } \\
\text { not applied }\end{array}$ & $\begin{array}{c}\text { Applied to evaluate } \\
\text { FCL }\end{array}$ & $\begin{array}{l}\text { Applied to evaluate } \\
\text { SRS of fighters }\end{array}$ & $\begin{array}{l}\text { Applied to obtain } \\
\text { aerodynamic } \\
\text { derivatives }\end{array}$ & $\begin{array}{l}\text { Applied to Investigate } \\
\text { A/FD CM and develop } \\
\text { and evaluate FCL }\end{array}$ \\
\hline
\end{tabular}

FCL: flight control law; SRS: spin recovery strategies; A/FD CM: coupling mechanisms of aerodynamics and flight dynamics; AFM: aerodynamic forces and moments; GCS: guidance and control system; ACS: attitude control system; and ACT: attitude control tests.

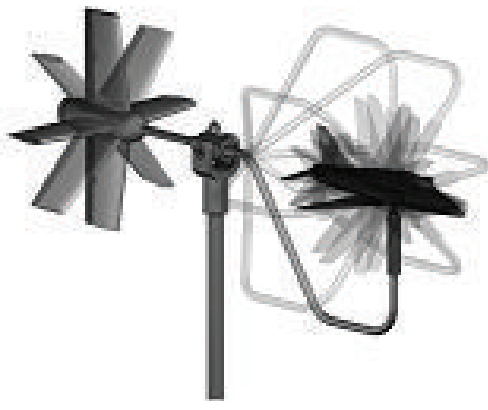

(a) Roll

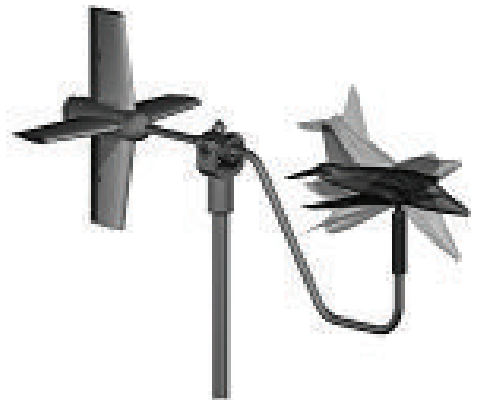

(b) Pitch

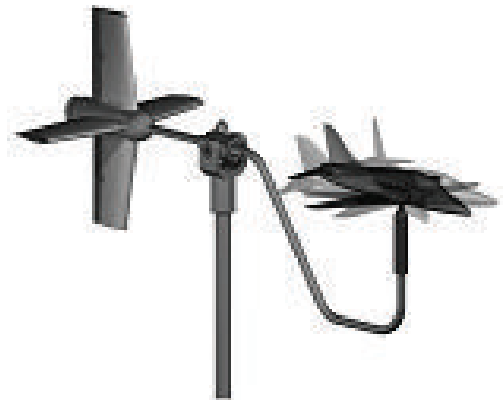

(c) Yaw

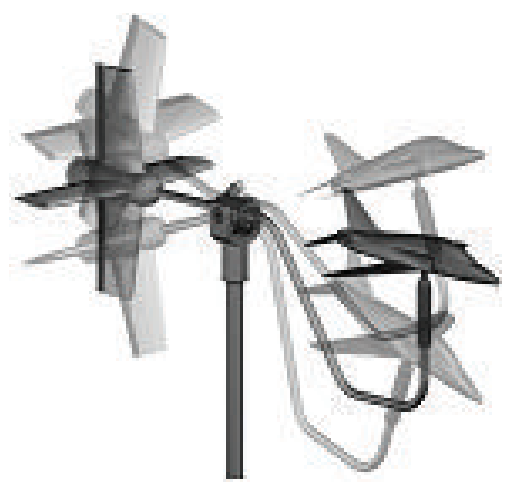

(d) Heave

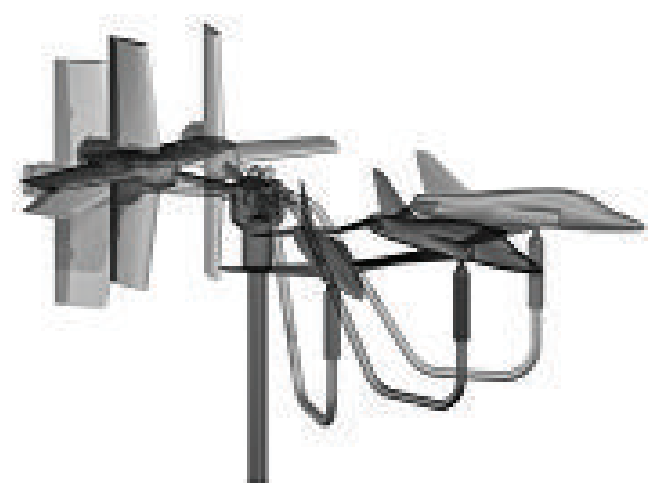

(e) Sway

FigURE 20: Illustration of the five available degrees of freedom [108].

guidance and control system with VFT, which has not been applied.

\section{Test System and Key Technologies of VFT for Evaluating FCS}

3.1. A Complete VFT Test System for Evaluating FCS. A complete VFT test system for evaluating FCS consists of a wind tunnel facility, a dark chamber, a real-time data acquisition and control system (in this paper, we call it real-time system in short), and simulation equipment, as shown in Figure 29. The model on the model support rig can freely pitch, yaw, and roll. The FCS kinds of hardware (i.e., sensors, controller, and servos) are put inside the wind tunnel model. The realtime system receives, processes, and transmits signals (such as the sensor signals, the control command signal) and controls relevant equipment (such as the wind tunnel facility, the model support system, the simulation computer, and the 


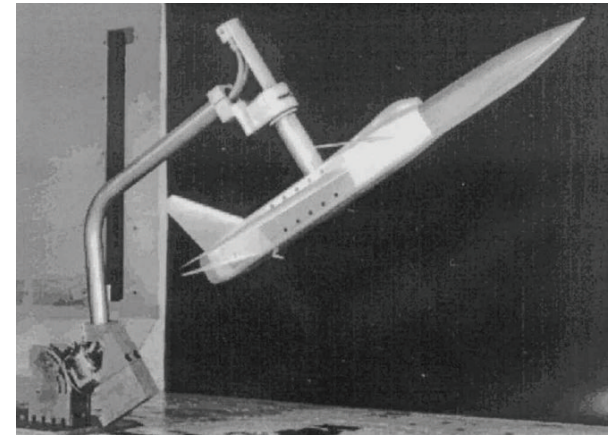

FIGURE 21: Photograph of the 2-DOF rig in the University of Cambridge [112].

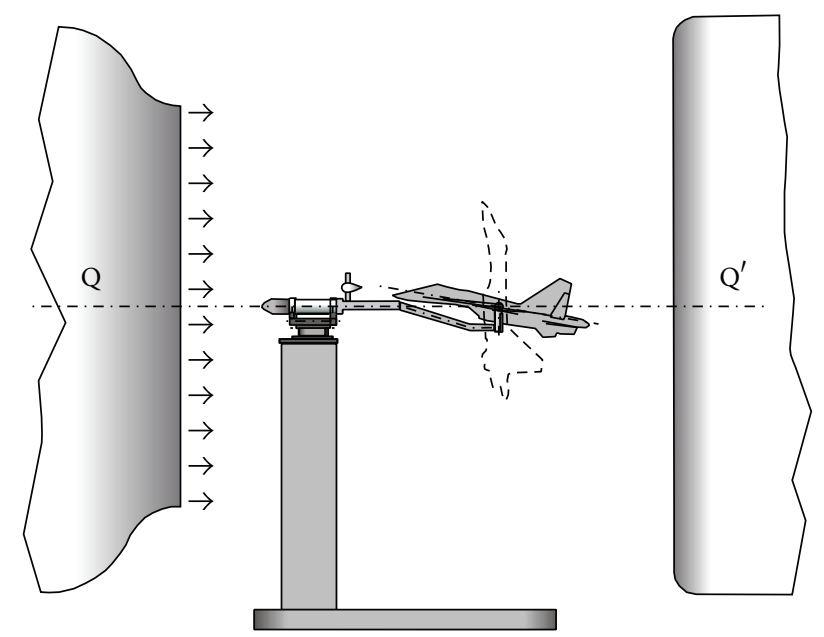

FIGURE 22: Three-degree-of-freedom rig for spin recovery investigation in the SibNIA T-203 wind tunnel [114].

three-axis turntable) and test process so as to guarantee the whole test run in real time. Simulation equipment includes a flight trajectory/target properties simulation computer, a target simulator, and a three-axis turntable. The flight trajectory/target properties simulation computer is used to calculate aircraft's flight trajectory and target properties after gathering aerodynamic forces and attitude information of the aircraft model transmitted by the real-time system. The target simulator is used to simulate target's properties physically so as to provide a living target environment for the seeker. The three-axis turntable is used to simulate aircraft's attitude motion for the seeker to track the target dynamics. The aircraft model with the seeker, the three-axis turntable, and the target simulator are all installed inside the dark chamber, which is a quasi-free space used for free transmission of electromagnetic waves.

With the wind tunnel facility, FCS hardware, and the realtime system, closed attitude control loop can be constituted, which can be used to evaluate attitude control systems and flight qualities. With the flight trajectory/target properties simulation computer and the dark chamber added, closed guidance control loop can be constituted, which can be used to evaluate guidance and control system and flight performances, such as target tracking performances. In actual applications, we should cut or add some compositions to build a VFT test system in accordance with evaluation requirements.

3.2. Key Technologies of VFT. The developing process of VFT technique for evaluating FCS can be divided into three steps: (1) determine evaluation contents, and research VFT evaluation methods; (2) based on the evaluation methods, design the overall scheme of VFT system and build the VFT test system; and (3) after building the VFT system, evaluate FCS performances with the VFT evaluation methods. Therefore, to evaluate FCS with VFT, key technology issues have to be addressed. They are VFT evaluation methods and key technologies of VFT test system including model scale technique, FCS related techniques, and model support technique. Brief introductions are given below.

(1) VFT Evaluation Methods of FCS. Once a VFT system is built, VFT tests can be conducted to evaluate the FCS performances. Investigations about how to evaluate FCS performances with simulation tests and flight tests can be found in many literatures [42-82], but VFT evaluation methods are hardly seen in published literatures. Therefore, methods for evaluating FCS performances with VFT have to be investigated and used for practical applications. Concluded from other ground test or flight test evaluation methods, a VFT evaluation method should consist of three parts: VFT test method, VFT data processing method, and FCS performance determination method. VFT test method is a guide for performing VFT tests so as to collect enough original data. VFT data processing method is a guide for converting the record original data to the data type needed for FCS performance evaluation. FCS performance determination method is a series of performance evaluation criteria used for determining the FCS performances based on the processed data.

(2) Model Scale Technique. Due to the limitation of the test section size of wind tunnel, the test model usually has to be scaled. But before scaling, a set of similarity criterions have to be satisfied. And the VFT model has to be fitted with some embedded devices, such as airborne sensors and servo systems, which will influence the mass distribution of the test model when the model is scaled. Moreover, the model is connected to a bearing support system, which makes the model scale more complicated. Considering the above factors, how to design and manufacture a dynamic scaled model satisfying the mass and inertia requirements and coordinated with other systems (such as the model embedded devices and model support system) is a key problem for VFT. Among the built VFT systems throughout the world, the majority of the test models are scaled, such as the 1/16-scaled Hawk model designed by University of Bristol [105]. But if the aircraft is not too big and the wind tunnel test section is big enough, such as the United States' air-to-air BOA missile placed in front of the HiVAS facility [91], the test model needs not to be scaled and the design of the model will be simplified greatly. 


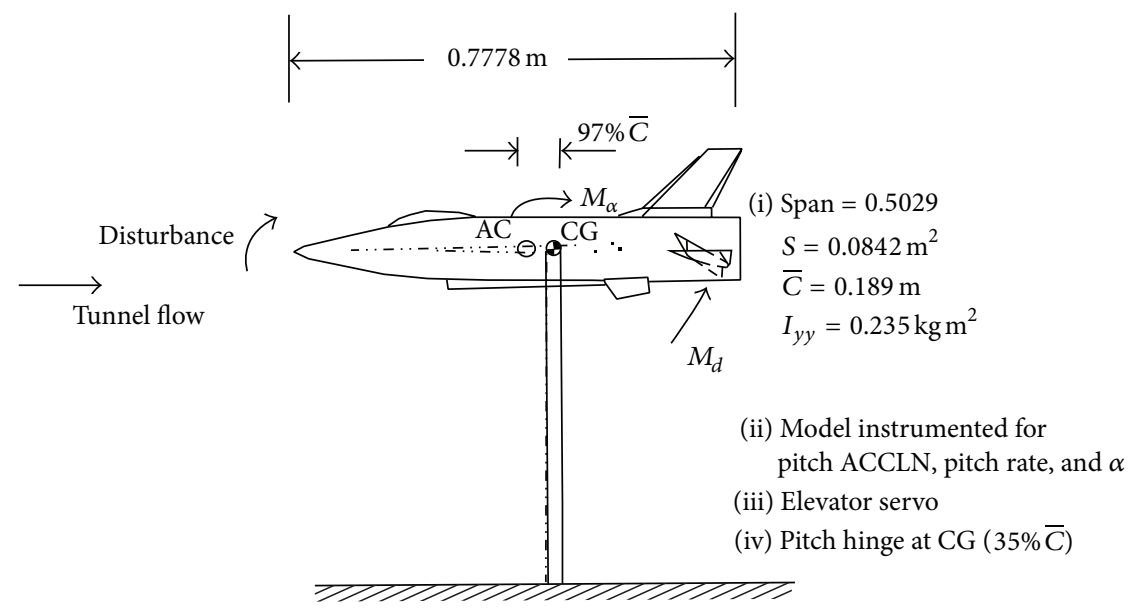

FIGURE 23: Single pitch DOF rig in NAL for demonstrating the unstable model dynamic wind tunnel flying method [115].

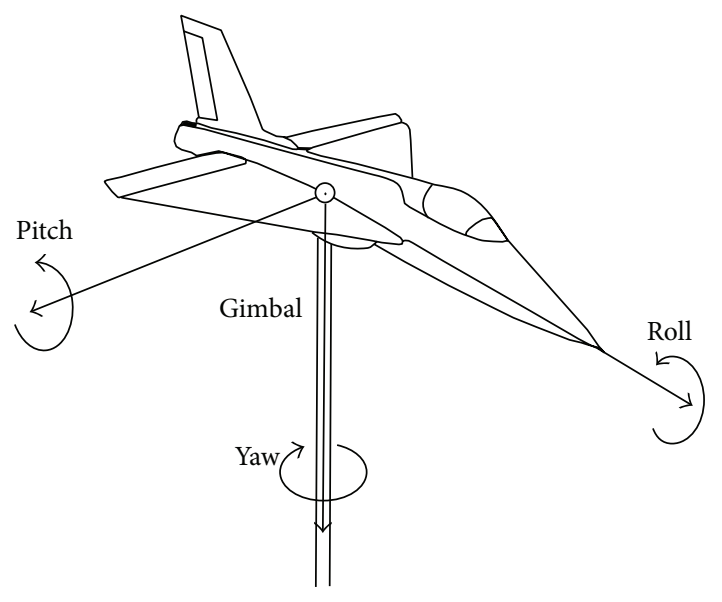

FIgURE 24: 3-DOF rig used for achieving Dynamic Wind Tunnel Simulation in NAL [116].

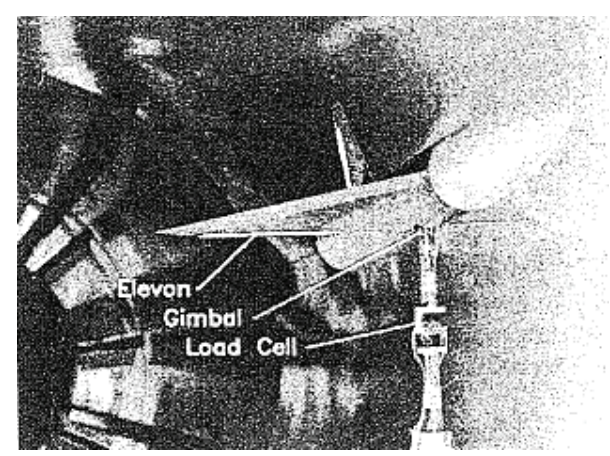

FIGURE 25: Single pitch DOF rig in NAL for obtaining comprehensive longitudinal aerodynamic data [117].

(3) FCS Related Techniques. Due to the differences between the VFT flying environment and the real free-flight environment in the air, the FCS cannot be directly put into the VFT

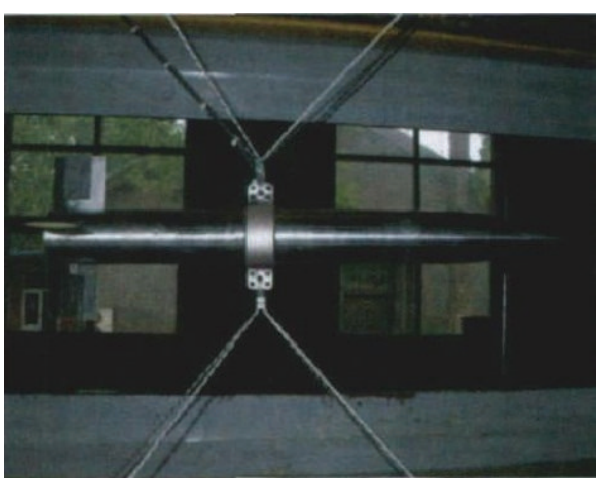

FIgURE 26: The first VFT system built by CAAA in China [118].

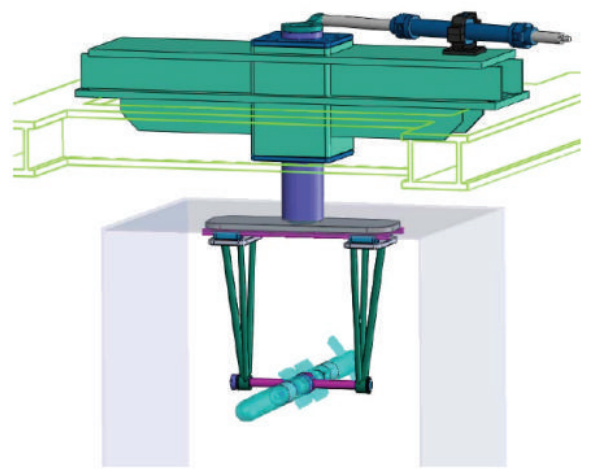

FIGURE 27: Sketch map of the 3-DOF rig developed by High Speed Aeronautics Institution in CARDC [120].

system. Some modifications have to be made to the FCS so as to ensure the consistency of VFT and free-flight in the air. The specific modifications are as follows:

(a) Actuator Scale Technique. If the test model is scaled, the actuators of FCS also need to be scaled. Therefore, 


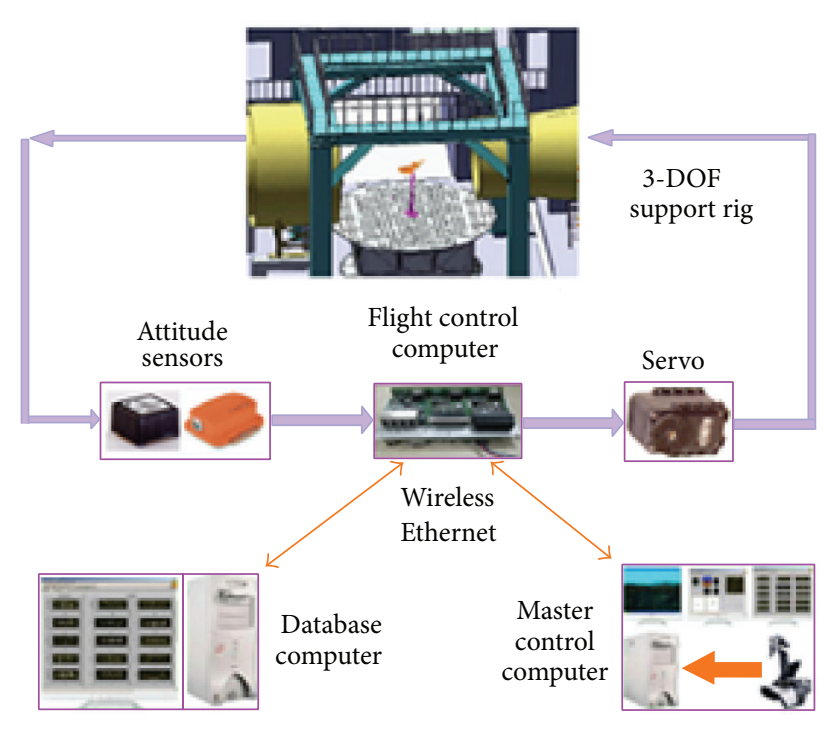

Figure 28: Scheme of VFT system designed by Low Speed Aeronautics Institution in CARDC [121].

the similitudes between the scaled actuators and the original ones have to be researched so as to guarantee their consistency. So far, such an investigation is hardly found in open literatures.

(b) Measuring Technique. The sensors of FCS in VFT are different from the real ones. Due to the limitation of translational motions in wind tunnel, the linear acceleration sensors have to be substituted by an aerodynamic force balance which measures the axial force, normal force, and lateral force to provide equivalent linear accelerations by combining other forces acting on the aircraft, such as the thrust. As for the measurement of attitude responses, not only gyros which measure attitude rates but also some other attitude sensors, such as optical encoders measuring the attitude angles, can be used. For instance, the VFT system developed by the PSI includes two optical encoders which are used to measure roll angle and pitch angle, respectively [93].

(c) Rapid Control Prototyping Technique. Before controller hardware is developed, a control prototype is needed to carry various flight control laws. To achieve this goal, rapid control prototyping technique is often adopted. It can rapidly build controller model and is quite suitable for evaluating FCS performances in the situation that controller hardware is not developed. The existing VFT systems adopting this technique are the dSPACE based VFT systems from the University of Bristol [103-110, 122] and the VxWorks based VFT system from the Low Speed Aeronautics Institution in CARDC [121].

(d) The Generality Requirement of FCS Hardware. If a VFT system is required to evaluate flight control laws from different aircraft types, the hardware of FCS ought to have generality. That is to say, the controller, attitude sensors, and servos are not from a special aircraft but should be specially designed so that the VFT system can be applied for evaluating different aircraft's flight control laws.

(e) The Real-Time Running Requirement of FCS. As the FCS evaluation requires real-time operation of the test, a real-time system is needed for real-time data acquisition and control, as shown in Figure 29.

(4) Model Support Technique. Several factors have to be considered when designing a model support system.

Firstly, the model support system has to ensure the model rotates freely around the CG of the test model. The rotational motions include free pitch, free yaw, and free roll, which can be allowed by gimbals or bearings. If bearings are not suitable for being installed on a certain rotation degree of freedom, then a forcing mechanism is needed to provide an equivalent free motion, as shown in Figure 1.

Secondly, the aerodynamic interference brought to the model configuration by the support system should be reduced as much as possible. Therefore, due to the lower aerodynamic interference of a wire support system compared with the model support system with a solid strut, the wire support system is chosen by many research departments, such as the support system developed by AEDC and PSI [90-95], CAAA [118]. When a certain form of support system is fixed, such as the wire support system, the aerodynamic interference also needs to be considered when designing the structure of model support system. For instance, in the PSI VFT system [93], to avoid the substantial aerodynamic interference produced by yaw bearings, the yaw bearings are removed, which leads to the fact that the free yaw motion has to be provided by a set of hydraulic modules to pull or relax the cables. Though this makes the support system design more complicated, reducing the aerodynamic interference of support system is more important, which will help obtain a better test result.

Thirdly, if bearings are used, the impact of bearing friction on model dynamics should be considered when designing the model support system. To reduce the impact of bearing friction, we can increase the aerodynamic spring and damping terms or increase the coefficients of the dynamic equations, the model size, and the test velocity. Brief analysis can be found in [93].

Finally, there are some other technique requirements for a model support system, such as the bearable load and the attitude angle range requirements of the bearings and the strength and stiffness requirements of the model support rig. These requirements need to be clearly listed when designing a specific support system.

Among the above key technologies, the model support technique is the core one. From the development history of the VFT in the United States, we can get to know that the development of VFT is in fact a process of continuous improving of the model support rig. The design of a model support system is complicated and very difficult. If we want to realize supersonic and hypersonic VFT tests, model support problems must be solved first. The overcome of this technique will greatly push the development of VFT techniques. 


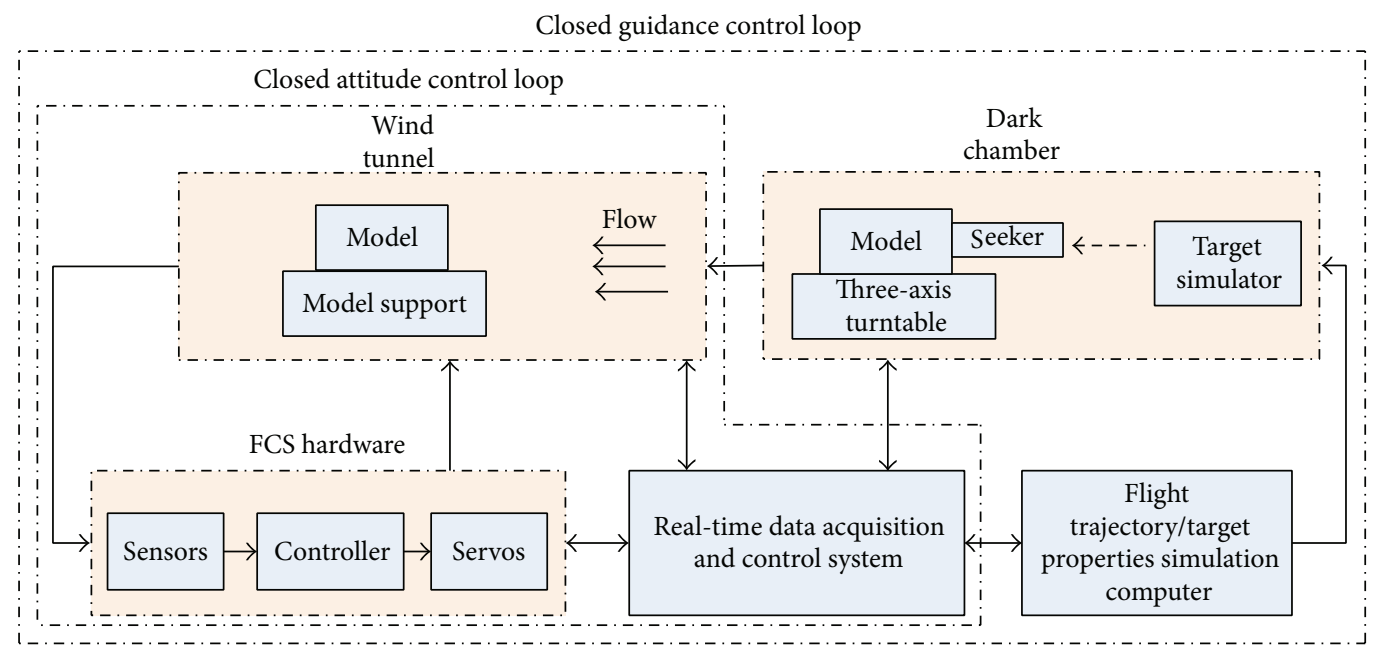

FIGURE 29: Compositions of a complete VFT system.

\section{Prospects of VFT for Evaluating FCS}

As can be seen from the progress of VFT, the history of VFT techniques is quite short, many key technologies need to be further investigated, and some new test capabilities with VFT will be realized, which are introduced as follows:

(1) Investigating VFT Evaluation Methods of FCS. Due to the apparent advantages of VFT, the application of VFT for evaluation of FCS will become more and more popularized just like the popularity of HILS at present. In this way, VFT evaluation methods of FCS are necessary and deserved to be investigated.

(2) Future Development of Model Support Techniques. Up to now, there are mainly two types of model support system for VFT: solid strut system with bearings [96-117, 120-122] and wire suspension system with bearings $[91-95,118]$. These support systems will more or less produce some aerodynamic interference for the test model. Therefore, optimum methods can be used in the design of a model support system to reduce the aerodynamic interference as much as possible. Moreover, quantification methods of the aerodynamic interference of the built support system must be investigated in order to attenuate its effects or to properly account for it in the interpretation of test results. Some kinds of model support systems which can eliminate aerodynamic interference can be investigated, such as the magnetic suspension systems. These systems had been used as magnetic suspension and balance systems (MSBS) for measuring aerodynamic forces and moments in [123-128].

(3) Realization of Guidance Control VFT. With VFT, two most potential tests are attitude control tests and guidance control tests [92]. The attitude control virtual flight tests have been demonstrated and conducted in open and closed control loop, respectively [91-120, 122], and have been applied for estimating aerodynamic derivatives [100-102, 106-108, 115117], investigating spin recovery strategies [113, 114], and evaluating flight control laws of aircraft types [103, 109-112]. However, guidance control tests are hardly seen in published literatures. In order to evaluate the guidance and control system with VFT, the guidance control VFT technique with simulated physical characteristics of targets (see Figure 29) has to be achieved in the future.

(4) Realization of Supersonic and Hypersonic VFT. So far, low speed, subsonic, and even transonic VFT tests have been performed, but supersonic and hypersonic VFT tests are hardly seen. As for future development trend, the test $\mathrm{Ma}$ of VFT will gradually reach the supersonic and hypersonic speed.

\section{Conclusions}

VFT is very promising for evaluating FCS performances. Through introducing the differences among VFT, traditional dynamic wind tunnel tests in FCS evaluation, and traditional FCS evaluation methods, the advantages of VFT are presented. VFT greatly broadens the capabilities of dynamic wind tunnel tests. One most notable capability added is that the evaluation of guidance and control system of aircraft at various speed areas can be achieved by VFT, while this is almost unable to be achieved by traditional dynamic wind tunnel tests, such as wind tunnel free-flight test with power. The test environment of VFT is more realistic than that of traditional simulation evaluation methods, such as HILS, so that the reliability of FCS for flight test will be further increased. Therefore, VFT will further reduce the risk of flight tests and cut down the development cycle and cost of FCS.

By introducing and analyzing the development histories of VFT in several main countries developing VFT techniques, the VFT state of the art is summarized, including the VFT research purposes, model support technique, measuring technique, test progress, and research status of these countries. After surveying the status of VFT, a possible complete VFT test system is conceived, and key technologies of VFT for FCS evaluation are summarized, including VFT evaluation 
methods, the model scale technique, FCS related techniques, and the model support technique. At length, some key technologies and test capabilities of VFT which are to be developed are pointed out. For the future, no matter what kind of VFT technique for evaluation of FCS we want to realize, supersonic or hypersonic VFT, the key technology problems mentioned in this paper must be solved.

\section{Conflict of Interests}

The authors declare that there is no conflict of interests regarding the publication of this paper.

\section{Acknowledgments}

The authors are grateful for the support by the Science Foundation of National University of Defense Technology (no. JC15-01-02) and the National Natural Science Foundation of China (no. 51505487). The authors also gratefully acknowledge the help of Zhen-yun Guo and Hao Wang and their selfless contributions of revising this paper.

\section{References}

[1] T. E. Manning, C. L. Ratliff, and E. J. Marquart, "Bridging the gap between ground and flight tests: virtual flight testing (VFT)," in Proceedings of the 1st AIAA Aircraft Engineering, Technology, AIAA-95-3875, 1995.

[2] M. Bacic and M. MacDiarmid, "Hardware-in-the-loop simulation of aerodynamic objects," in Proceedings of the AIAA Modeling and Simulation Technologies Conference and Exhibit, AIAA 2007-6465, Hilton Head, SC, USA, August 2007.

[3] F. Boria, B. Stanford, S. Bowman, and P. Ifju, "Evolutionary optimization of a morphing wing with wind-tunnel hardware in the loop," AIAA Journal, vol. 47, no. 2, pp. 399-409, 2009.

[4] N. R. Gans, W. E. Dixon, R. Lind, and A. Kurdila, "A hardware in the loop simulation platform for vision-based control of unmanned air vehicles," Mechatronics, vol. 19, no. 7, pp. 10431056, 2009.

[5] F. Liu, L. Wang, and X. Tan, "Digital virtual flight testing and evaluation method for flight characteristics airworthiness compliance of civil aircraft based on HQRM," Chinese Journal of Aeronautics, vol. 28, no. 1, pp. 112-120, 2015.

[6] C. L. Ratliff and E. J. Marquart, "An assessment of a potential test technique: virtual flight testing (VFT)," in Proceedings of the AIAA Flight Simulation Technologies Conference, AIAA-95-3415, 1995.

[7] D. B. Owens, J. M. Brandon, M. A. Croom, C. M. Fremaux, E. H. Heim, and D. D. Vicroy, "Overview of dynamic test techniques for flight dynamics research at NASA LaRC," in Proceedings of the 25th AIAA Aerodynamic Measurement Technology and Ground Testing Conference, AIAA 2006-3146, 2006.

[8] R. A. Kilgore and B. T. Averett, "A forced-oscillation method for dynamic-stability testing," Journal of Aircraft, vol. 5, no. 1, pp. 304-305, 1964.

[9] G. E. Burt, "A forced-oscillation test mechanism for measuring dynamic-stability derivatives in roll," in Proceedings of the 12th AIAA Aerospace Sciences Meeting, AIAA-74-86, 1974.
[10] L. E. Ericsson and M. E. Beyers, "Wind-tunnel aerodynamics in rotary tests of combat aircraft models," Journal of Aircraft, vol. 35, no. 4, pp. 521-528, 1998.

[11] D. J. Piatak and C. S. Cleckner, "A new forced oscillation capability for the transonic dynamics tunnel," in Proceedings of the 40th AIAA Aerospace Sciences Meeting \& Exhibit, AIAA 2002-0171, 2002.

[12] G. Hoe, D. B. Owens, and C. Denham, "Forced oscillation wind tunnel testing for FASER flight research aircraft," in Proceedings of the AIAA Atmospheric Flight Mechanics Conference, AIAA 2012-4645, 2012.

[13] D. Regodić, M. Samardžić, and G. Grubor, "Review of the rolldamping, measurements in the T-38 wind tunnel," Journal of Scientific and Research Publications, vol. 12, no. 3, pp. 1-6, 2013.

[14] A. S. Pototzky and P. C. Murphy, "Roll damping derivatives from generalized lifting-surface theory and wind tunnel forcedoscillation tests," in Proceedings of the AIAA Atmospheric Flight Mechanics Conference, AIAA 2014-0731, 2014.

[15] J. Kalviste, "Use of rotary balance and forced oscillation test data in a six degrees of freedom simulation," in Proceedings of the AIAA 9th Atmospheric Flight Mechanics Conference, AIAA-82$1364,1982$.

[16] W. B. Blake, "A study of the rotary balance technique for predicting pitch damping," in Proceedings of the AIAA Atmospheric Flight Mechanics Conference, AIAA-93-3619-CP, 1993.

[17] G. N. Malcolm, B. R. Kramer, and C. J. Suhrez, "US/UK rotarybalance test comparisons with a generic fighter model," in Proceedings of the 32nd Aerospace Sciences Meeting \& Exhibit, AIAA 94-0196, 1994.

[18] W. J. Gillard, "Innovative control effectors (configuration 101) dynamic wind tunnel test report. Rotary balance and forced oscillation tests," Air Force Research Lab Wright-Patterson AFB OH Air Vehicles Directorate AFRL-VA-WP-TR-1998-3043, 1998.

[19] R. L. Morris, "Utilization of a free oscillation wind tunnel model in conjunction with an analog computer to determine the dynamic stability derivatives," in Proceedings of the 2 nd AIAA Aerodynamic Testing Conference, AIAA-66-770, 1966.

[20] K. F. Stetson and F. M. Sawyer, "A comparison of hypersonic wind tunnel data obtained by static and free oscillation techniques," in Proceedings of the AIAA 10th Fluid \& Plasmadynamics Conference, AIAA-77-690, Albuquerque, NM, USA, 1977.

[21] T. Yoshinaga, K. Inoue, and A. Tate, "Determination of the pitching characteristics of tumbling bodies by the free-rotation method," Journal of Spacecraft and Rockets, vol. 21, no. 1, pp. 2128, 1984.

[22] R. M. Howard, T. R. DeMoss, D. D. Lack, and R. B. Caldwell, "Tumbling susceptibility of a tailless unmanned air vehicle," in Proceedings of the AIAA Atmospheric Flight Mechanics Conference and Exhibit, AIAA 2002-4615, Monterey, Calif, USA, 2002.

[23] F. J. Capone, D. Bruce Owens, and R. M. Hall, "Development of a transonic free-to-roll test capability," Journal of Aircraft, vol. 41, no. 3, pp. 456-463, 2004.

[24] D. B. Owens, J. K. McConnell, J. M. Brandon, and R. M. Hall, "Transonic free-to-roll analysis of the F-35 (joint strike fighter) aircraft," Journal of Aircraft, vol. 43, no. 3, pp. 608-615, 2006.

[25] D. Tang and E. H. Dowell, "Effects of a free-to-roll fuselage on wing flutter: theory and experiment," AIAA Journal, vol. 52, no. 12, pp. 2625-2632, 2014. 
[26] P. C. Boisseau, "Flight investigation of dynamic stability and control characteristics of a 1/10-scale model of a variable-wingsweep fighter airplane configuration," National Aeronautics and Space Administration NASA TM X-1367, NASA, 1967.

[27] S. B. Grafton and J. R. Cbamber, "Wind-tunnel free-flight investigation of a model of a spin-resistant fighter configuration," NASA TN D-7716, National Aeronautics and Space Administration (NASA), 1974.

[28] L. P. Parlett, "Free-flight wind-tunnel investigation of four engine swept wing upper-surface blown transport configuration," NASA TN D-8479, National Aeronautics and Space Administration (NASA), 1977.

[29] D. G. Murri, L. T. Nguyen, and S. B. Grafton, "Wind-tunnel freeflight investigation of a model of a forward-swept-wing fighter configuration," National Aeronautics and Space Administration NASA TP-2230, NASA, 1984.

[30] J. M. Brandon, J. M. Simon, D. B. Owens, and J. S. Kiddy, "Free-flight investigation of fore-body blowing for stability and control," in Proceedings of the AIAA Atmospheric Flight Mechanics Conference, AIAA-96-3444, San Diego, Calif, USA, 1996.

[31] Y. Kikmoto and O. Kobayasgi, "Free flight of airplane in wind tunnel," in Proceedings of the Aircraft Symposium, 2000.

[32] P. W. Gregory and A. A. David, "X-35B STOVL flight control law design and flying qualities," in Proceedings of the Biennial International Powered Lift Conference and Exhibit, AIAA 20026018, Williamsburg, VA, USA, November 2002.

[33] H. Sakata and O. Kobayasgi, "Free flight of airplane in wind tunnel (second report)," in Proceedings of the Aircraft Symposium, 2003.

[34] E. B. Jackson and C. W. Buttrill, Control Laws for a Wind Tunnel Free-Flight Study of a Blended-Wing-Body Aircraft, National Aeronautics and Space Administration (NASA), 2006.

[35] A. S. Platou, "The wind tunnel free flight testing technique," in Proceedings of the AIAA 3rd Aerodynamic Testing Conference, AIAA-68-388, 1968.

[36] D. E. Hahne, T. R. Wendel, and J. R. Boland, "Wind-tunnel free-flight investigation of a supersonic persistence fighter," NASA Technical Paper 3258, National Aeronautics and Space Administration (NASA), 1993.

[37] T. Hideyuki, K. Tomoyuki, S. Kazuo et al., "Free-flight force measurement technique in shock tunnel," in Proceedings of the 50th AIAA Aerospace Sciences Meeting Including the New Horizons Forum and Aerospace Exposition (AIAA '12), AIAA 2012-1241, Nashville, Tenn, USA, January 2012.

[38] S. J. Laurence, J. M. Schramm, and K. Hannemann, "Force and moment measurements on a free-flying capsule model in a high-enthalpy shock tunnel," in Proceedings of the 28th Aerodynamic Measurement Technology, Ground Testing, and Flight Testing Conference, AIAA 2012-2861, New Orleans, La, USA, June 2012.

[39] N. R. Mudford, S. O'Byrne, A. Neely, D. Buttsworth, and S. Balage, "Hypersonic wind-tunnel free-flying experiments with onboard instrumentation," Journal of Spacecraft and Rockets, vol. 52, no. 1, pp. 231-242, 2015.

[40] D. Owens, Spin-Tunnel Investigation of a 1/28-Scale Model of the LTV YA-7F Airplane, (NASA CR-198225), National Aeronautics and Space Administration (NASA), 1995.

[41] C. M. Fremaux, D. M. Vairo, and R. D. Whipple, "Effect of geometry and mass distribution on tumbling characteristics of flying wings," Journal of Aircraft, vol. 32, no. 2, pp. 404-410, 1995.
[42] M. E. Sisle, "Analysis and evaluation of patriot guidance and control," in Proceedings of the Guidance and Control Conference, San Diego, Calif, USA, 1976.

[43] Y. Sakai, S. Suzuki, M. Miwa, and T. Tsuchiya, "Flight test evaluation of non-linear dynamic inversion controller," in Proceedings of the 46th AIAA Aerospace Sciences Meeting and Exhibit, AIAA 2008-209, Reno, Nev, USA, January 2008.

[44] N. Dadkhah and B. Mettler, "Control system design and evaluation for robust autonomous rotorcraft guidance," Control Engineering Practice, vol. 21, no. 11, pp. 1488-1506, 2013.

[45] H. Suzuki and Y. Matsumoto, "Development of flight simulation program for the HYFLEX vehicle and flight analysis," National Aerospace Laboratory of Japan NAL TR-1317, 1997.

[46] J. Georgie and J. Valasek, "Evaluation of longitudinal desired dynamics for dynamic-inversion controlled generic reentry vehicles," Journal of Guidance, Control, and Dynamics, vol. 26, no. 5, pp. 811-819, 2003.

[47] J. Janardanan and M. Jayakumar, "Robust longitudinal flight controller design for a hypersonic re-entry vehicle," in Proceedings of the 14th AIAA/AHI Space Planes and Hypersonic Systems and Technologies Conference (AIAA '06), AIAA 20068076, 2006.

[48] E. R. Mueller, "Hardware-in-the-loop simulation design for evaluation of unmanned aerial vehicle control systems," in Proceedings of the AIAA Modeling and Simulation Technologies Conference and Exhibit, AIAA 2007-6569, Hilton Head, SC, USA, August 2007.

[49] S. Suresh and N. Kannan, "Direct adaptive neural flight control system for an unstable unmanned aircraft," Applied Soft Computing Journal, vol. 8, no. 2, pp. 937-948, 2008.

[50] W. F. Wang, P. P. Menon, and D. G. Bates, "Verification and validation of attitude and orbit control systems for flexible satellites," in Proceedings of the AIAA Guidance, Navigation, and Control Conference, AIAA 2009-5953, Chicago, Ill, USA, 2009.

[51] P. P. Menon, I. Postlethwaite, S. Bennani, A. Marcos, and D. G. Bates, "Robustness analysis of a reusable launch vehicle flight control law," Control Engineering Practice, vol. 17, no. 7, pp. 751$765,2009$.

[52] H. D. Joos and H. Pfifer, "Robust flight control system design verification and validation by multiobjective worst-case search," in Proceedings of the AIAA Guidance, Navigation, and Control Conference, AIAA 2012-4998, Minneapolis, Minn, USA, August 2012.

[53] Y. C. Paw and G. J. Balas, "Development and application of an integrated framework for small UAV flight control development," Mechatronics, vol. 21, no. 5, pp. 789-802, 2011.

[54] I. Prodan, S. Olaru, R. Bencatel, J. Borges de Sousa, C. Stoica, and S.-I. Niculescu, "Receding horizon flight control for trajectory tracking of autonomous aerial vehicles," Control Engineering Practice, vol. 21, no. 10, pp. 1334-1349, 2013.

[55] M. E. Sisle and R. Baldwin, "Guidance system evaluation techniques for SAM-D," in Proceedings of the AIAA Guidance and Control Conference, AIAA-73-877, Key Biscayne, Fla, USA, 1973.

[56] H. L. Pastrick, C. M. Will, L. Isom, A. Jolly, L. Hazel, and R. Vinson, "Hardware-in-the-loop simulation: a guidance system optimization tool," in Proceedings of the AIAA Mechanics and Control of Flight Conference, AIAA-74-929, Huntsville, Ala, USA, 1974.

[57] R. M. Gravitz and W. F. Waite, "Validation methodologies for complex, hybrid, HWIL, 6DOF missile simulations-a 
structured approach," in Proceedings of the 20th Conference on Winter Simulation, pp. 775-782, IEEE, December 1988.

[58] J. Kouchiyama, Y. Funo, S. Ogawa, T. Fujiwara, M. Nishida, and K. Hasegawa, "Hardware-in-the-loop simulation for TR-I rocket roll control system," in Proceedings of the IFAC Symposium, AIAA-89-3623-CP, Seoul, Republic of Korea, 1989.

[59] M. E. Sisle and E. D. McCarthy, "Hardware-in-the-loop simulation for an active missile," Simulation, vol. 39, no. 5, pp. 159-167, 1982.

[60] R. Jackson and A. N. Vamivakas, "An overview of hardwarein-the-loop simulations for missile," in Proceedings of the AIAA GNC, AFM, and MST Conference and Exhibit, AIAA-97-37356, Austin, Tex, USA, 1997.

[61] S. K. Chaudhuri, G. Venkatachalam, and M. Prabhakar, "Hardware-in-loop simulation for missile guidance and control systems," Defence Science Journal, vol. 47, no. 3, pp. 343-356, 1997.

[62] H. Eguchi, K. Obana, and M. Kamiya, "Hardware-in-the-Loop missile simulation facility," in Proceedings of the Technologies for Synthetic Environments: Hardware-in-the-Loop Testing III, R. L. Murrer, Ed., vol. 3368 of Proceedings of SPIE, July 1998.

[63] K. Ćosić, I. Kopriva, T. Kostić, M. Slamić, and M. Volarević, "Design and implementation of a hardware-in-the-loop simulator for a semi-automatic guided missile system," Simulation Practice and Theory, vol. 7, no. 2, pp. 107-123, 1999.

[64] X. Y. Yang, J. Y. Wang, and H. L. Luo, "A hardware-in-the-loop simulation platform of an imaging ATR missile," in Proceedings of the Asia Simulation Conference, 7th International Conference on System Simulation and Scientific Computing, (ICSC '08), pp. 545-550, IEEE, Beijing, China, October 2008.

[65] W. C. Filllo, L. R. Mallacot, and D. S. Carrijo, "Hardware in the loop simulation of an attitude control system," in Proceedings of the AIAA Modeling and Simulation Technologies Conference and Exhibit, AIAA-99-4323, Portland, Ore, USA, August 1999.

[66] P. Tobbe, A. Matras, D. Walker et al., "Real-time hardwarein-the-loop simulation of ares i launch vehicle," in Proceedings of the AIAA Modeling and Simulation Technologies Conference, AIAA 2009-6130, Chicago, Ill, USA, August 2009.

[67] W. B. Huang and Q. Zhang, "The hardware-in-the-loop simulation on the control system of a small launch vehicle," Procedia Engineering, vol. 29, pp. 1867-1871, 2012.

[68] S. A. Kowalchuk, "Model-based design strategies for realtime hardware-in-the-loop rocket system simulations," in Proceedings of the AIAA Modeling and Simulation Technologies Conference, AIAA 2012-4627, Minneapolis, Minn, USA, 2012.

[69] J. S. Jang and C. J. Tomlin, "Autopilot design for the Stanford DragonFly UAV: validation through hardware-in-the-loop simulation," in Proceedings of the AIAA Guidance, Navigation, and Control Conference and Exhibit, AIAA 2001-4179, Montreal, Canada, August 2001.

[70] B. Kim, E. Velenis, P. Kriengsiri, and P. Tsiotras, "Designing a low-cost spacecraft simulator," IEEE Control Systems Magazine, vol. 23, no. 4, pp. 26-37, 2003.

[71] Y. Sakai, S. Suzuki, M. Miwa, T. Tsuchiya, K. Masui, and H. Tomita, "Flight test evaluation of non-linear dynamic inversion controller," in Proceedings of the 46th AIAA Aerospace Sciences Meeting and Exhibit, AIAA 2008-209, Reno, Nev, USA, January 2008.

[72] O. Toupet and B. Mettler, "Design and flight test evaluation of guidance system for autonomous rotorcraft," in Proceedings of the AIAA Guidance, Navigation, and Control Conference, pp. 1288-1297, AIAA, August 2006.
[73] G. W. Cai, B. M. Chen, X. Dong, and T. H. Lee, "Design and implementation of a robust and nonlinear flight control system for an unmanned helicopter," Mechatronics, vol. 21, no. 5, pp. 803-820, 2011.

[74] G. G. Farris, V. K. Merrick, and R. M. Gerdes, "Simulation evaluation of flight controls and display concepts for VTOL shipboard operations," in Proceedings of the Guidance and Control Conference, AIAA-83-2173, 1983.

[75] H. N. Swenson, R. E. Zelenka, G. H. Hardy, and M. G. Dearing, "Simulation evaluation of a low-altitude helicopter flight guidance system adapted for a helmet-mounted display," NASA TM-103883, National Aeronautics and Space Administration (NASA), 1992.

[76] S. L. Graham, "Design analysis and methodology for evaluating flight control systems," in Proceedings of the AIAA/AHS/ASEE Aircraft Systems, Design \& Technology Meeting, AIAA-86-2655, 1986.

[77] E. Torenbeek and H. Wittenberg, Flight Physics, Springer, New York, NY, USA, 2009.

[78] L. M. Damman, "Flight test development and evaluation of a multimock digital flight control system in an A-7D (DIGITAC)," in Proceedings of the Aircraft Systems and Technology Meeting, AIAA-76-927, Dallas, Tex, USA, 1976.

[79] C. J. Scherz and P. B. Tucker, "Flight test evaluation of active ride control system tactical aircraft," in Proceedings of the AIAA Guidance, Navigation and Control Conference, AIAA-85-1860, Snowmass, Colo, USA, August 1985.

[80] H. Suzuki, S. Ishimoto, and T. Morito, "Postflight evaluation of the HYFLEX guidance, navigation and control," in Proceedings of the Space Plane and Hypersonic Systems and Technology Conference, AIAA-96-4525-CP, Norfolk, Va, USA, 1996.

[81] T. Ninomiya, H. Suzuki, and T. Tsukamoto, "Evaluation of guidance and control system of high speed flight demonstrator phase II," in Proceedings of the 13th AIAA/CIRA International Space Planes and Hypersonic Systems and Technologies Conference, pp. 673-681, May 2005.

[82] T. Ninomiya, H. Suzuki, and T. Tsukamoto, "Evaluation of guidance and control systems of a balloon-launched drop-test vehicle," Journal of Spacecraft and Rockets, vol. 43, no. 6, pp. 1423-1426, 2006.

[83] Y. Nam and S. K. Hong, "Force control system design for aerodynamic load simulator," Control Engineering Practice, vol. 10, no. 5, pp. 549-558, 2002.

[84] A. D. Ronch, M. Ghoreyshi, and K. J. Badcock, "On the generation of flight dynamics aerodynamic tables by computational fluid dynamics," Progress in Aerospace Sciences, vol. 47, no. 8, pp. 597-620, 2011.

[85] W. P. Schoenfeld and F. J. Priolo, "Automated wind tunnel testing," in Proceedings of the 36th AIAA Aerospace Sciences Meeting and Exhibit, AIAA 1998-709, Reno, Nev, USA, January 1998.

[86] J. C. Magill, K. R. McManus, M. G. Miller, and M. G. Allen, "A high bandwidth air bearing balance for dynamic wind tunnel testing," in Proceedings of the 22nd Atmospheric Flight Mechanics Conference, AIAA-97-3648, New Orleans, La, USA, 1997.

[87] F. C. Lawrence and E. J. Marquart, "Virtual flight testing (VFT) at the Arnold Engineering Development Center," in Proceedings of the ITEA 1999 Conference, Indianapolis, Ind, USA, March 1999.

[88] G. Gebert, J. Kelly, J. Lopez, and J. Evers, "Virtual flight testing in a ground test facility," in Proceedings of the 18th AIAA Applied Aerodynamics Conference, AIAA 2000-4019, 2000. 
[89] G. Gebert, J. Kelly, and J. Lopez, "Virtual flight test (VFT) modeling and assessment," TEAS Reference TR-9800723-90U, 1998.

[90] G. Gebert, J. Kelly, J. Lopez, and J. Evers, "Wind tunnel based virtual flight testing," in Proceedings of the 38th Aerospace Sciences Meeting \& Exhibit, AIAA 2000-46669, 2000.

[91] C. Lawrence and B. Mills, "Status update of the AEDC virtual flight testing development program," in Proceedings of the 40th AIAA Aerospace Sciences Meeting \& Exhibit (AIAA '02), AIAA 2002-0168, 2002.

[92] J. C. Magill and S. D. Wehe, "Initial test of a wire suspension mount for missile virtual flight testing," in Proceedings of the 40th AIAA Aerospace Sciences Meeting and Exhibit, AIAA, January 2002.

[93] J. C. Magill, P. Cataldi, J. R. Morency, D. X. Hammer, and B. D. Anderson, "Design of a wire suspension system for dynamic testing in AEDC 16T," in Proceedings of the 41st Aerospace Sciences Meeting and Exhibit, AIAA 2003-452, Reno, Nev, USA, January 2003.

[94] J. C. Magill, P. Cataldi, J. R. Morency, D. X. Hammer, R. Burgess, and E. Jeter, "Active yaw control with a wire suspension system for dynamic wind tunnel testing," in Proceedings of the 43rd AIAA Aerospace Sciences Meeting and Exhibit, AIAA 2005-1295, Reno, Nev, USA, 2005.

[95] J. C. Magill, P. Cataldi, J. R. Morency, D. X. Hammer, R. Burgess, and E. Jeter, "Demonstration of a wire suspension for windtunnel virtual flight testing," Journal of Spacecraft and Rockets, vol. 46, no. 3, pp. 624-633, 2009.

[96] H. Kumar, A preliminary study into the design of a free flight wind tunnel model for demonstrating the dynamic characteristics of aircraft [M.S. thesis], Cranfield Institute of Technology, 1980.

[97] I. A. Malik, The design, development and evaluation of an active control aircraft model wind tunnel facility [Ph.D. dissertation], Cranfield Institute of Technology, Cranfield, Uk, 1982.

[98] F. Heydari, On the estimation of stability and control characteristics of a generalized forward swept wing aircraft [Ph.D. dissertation], Cranfield Institute of Technology, 1986.

[99] M. V. Cook and F. Heydari, "The estimation of the stability and control characteristics of a canard configured combat aircraft having a forward swept wing," in Proceedings of the 15th Congress of the International Council of the Aeronautical Sciences, London, UK, 1986.

[100] M. V. Cook, "On the use of small scale aircraft models for dynamic wind tunnel investigation of stability and control," Transactions of the Institute of Measurement and Control, vol. 9, no. 4, pp. 190-197, 1987.

[101] S. D. Carnduff, S. D. Erbsloeh, A. K. Cooke, and M. V. Cook, "Development of a low cost dynamic wind tunnel facility utilizing MEMS inertial sensors," in Proceedings of the 46th AIAA Aerospace Sciences Meeting and Exhibit, January 2008.

[102] S. D. Carnduff, S. D. Erbsloeh, A. K. Cooke, and M. V. Cook, "Characterizing stability and control of subscale aircraft from wind-tunnel dynamic motion," Journal of Aircraft, vol. 46, no. 1, pp. 137-147, 2009.

[103] P. M. Davison and H. Mark, "Modelling and control of a single degree-of-freedom dynamic wind tunnel rig," in Proceedings of the European Control Conference, pp. 597-602, Cambridge, UK, September 2003.

[104] P. M. Davison, M. H. Lowenberg, and M. D. Bernardo, "Modelling non-linear behavior in a single degree-of-freedom dynamic wind tunnel rig," in Proceedings of the AIAA Atmospheric Flight Mechanics Conference, AIAA 2003-5314, Austin, Tex, USA, August 2003.

[105] M. H. Lowenberg and H. L. Kyle, "Development of a pendulum support rig dynamic wind tunnel apparatus," in Proceedings of the Atmospheric Flight Mechanics Conference and Exhibition (AIAA '02), AIAA-02-4879, 2002.

[106] A. Gatto and M. H. Lowenberg, "Evaluation of a three degree of freedom test rig for stability derivative estimation," Journal of Aircraft, vol. 43, no. 6, pp. 1747-1761, 2006.

[107] A. Gatto, "Application of a pendulum support test rig for aircraft stability derivative estimation," Journal of Aircraft, vol. 46, no. 3, pp. 927-934, 2009.

[108] J. Pattinson and M. H. Lowenbergy, "A multi-degree-offreedom rig for the wind tunnel determination of dynamic data," in Proceedings of the AIAA Atmospheric Flight Mechanics Conference, AIAA 2009-5727, Minneapolis, Minn, USA, August 2009.

[109] T. S. Richardson, A. Dubs, M. H. Lowenberg, and C. D. Jones, "Wind-tunnel testing of a dynamic state-feedback gain scheduled control system," in Proceedings of the AIAA Guidance, Navigation and Control Conference and Exhibition, AIAA 20055976, San Francisco, Calif, USA, 2005.

[110] P. M. Davison, M. H. Lowenberg, and M. Di Bernardo, "Experimental analysis and modeling of limit cycles in a dynamic windtunnel rig," Journal of Aircraft, vol. 40, no. 4, pp. 776-785, 2003.

[111] G. Papageorgiou and K. Glover, "Design, development and control of the HIRM wind tunnel model," in Proceedings of the 38th IEEE Conference on Decision and Control (CDC '99), pp. 1529-1537, IEEE, December 1999.

[112] G. Papageorgiou and K. Glover, "Two-degree-of-freedom control of an actively controlled wind-tunnel model," Journal of Guidance, Control, and Dynamics, vol. 25, no. 3, pp. 510-516, 2002.

[113] N. P. Sohi, Y. A. Prudnikov, and Y. N. Temlyakov, "Estimation of spin characteristics of aerobatic aircraft by means of spin modes modeling in a horizontal wind tunnel," in Proceedings of the 22th International Congress of the Aeronautical Sciences, 2002.

[114] N. P. Sohi, "Modeling of spin modes of supersonic aircraft in horizontal wind tunnel," in Proceedings of the 24th International Congress of the Aeronautical Sciences, Yokohama, Japan, September 2004.

[115] S. Balakrishna and T. Niranjana, "Wind tunnel dynamic flying study of the pitching moment derivatives of the standard dynamics model in active control," in Proceedings of the 14th Atmospheric Flight Mechanics Conference, AIAA 1987-2626, Monterey, Calif, USA, August 1987.

[116] S. Balakrishna, T. Niranjana, M. S. Rajamurthy, S. Srinathkumar, S. R. Rajan, and S. K. Singh, "Estimation of aerodynamic derivatives using dynamic wind tunnel simulation technique," in Proceedings of the NAL-DLR Symposium on System Identification, 1993.

[117] M. S. Rajamurthy, "Generation of comprehensive longitudinal aerodynamic data using dynamic wind-tunnel simulation," Journal of Aircraft, vol. 34, no. 1, pp. 29-33, 1997.

[118] J. Hu and Q. Li, "Primary investigation of the virtual flight testing techniques in wind tunnel," Journal of Experiments in Fluid Mechanics, vol. 24, no. 1, pp. 95-99, 2010 (Chinese).

[119] H. Li, Z. L. Zhao, and Z. L. Fan, "Simulation method for wind tunnel based virtual flight testing," in Proceedings of the International Symposium on Physics of Fluids (ISPF '12), 2012. 
[120] H. Li, Study on the similarity criteria and simulation method of the wind tunnel based virtual flight testing [Ph.D. dissertation], CARDC, Mianyang, China, 2012 (Chinese).

[121] B. W. Nie, M. H. Zhu, L. L. Guo, Y. C. Wen, and M. Jiang, "Key technique and design scheme of the wind tunnel virtual flight system," in Proceedings of the Chinese Guidance, Navigation and Control Conference (CGNCC '12), 2012 (in Chinese).

[122] J. Pattinson, M. H. Lowenberg, and M. G. Goman, "Multidegree-of-freedom wind-tunnel maneuver rig for dynamic simulation and aerodynamic model identification," Journal of Aircraft, vol. 50, no. 2, pp. 551-566, 2013.

[123] M. J. Goodyer, The magnetic suspension of wind tunnel models for dynamic tests [Ph.D. dissertation], University of Southampton, Southampton, UK, 1967.

[124] E. E. Covert, "Magnetic suspension and balance systems," IEEE Aerospace and Electronic Systems Magazine, vol. 3, no. 5, pp. 1422, 1988.

[125] P. L. Lawing and W. G. Johnson, "A forecast of new test capabilities using magnetic suspension and balance systems," in Proceedings of the 15th Aerodynamic Testing Conference, AIAA88-2013, 1988.

[126] C. P. Britcher, "Application of magnetic suspension technology to large scale facilities-progress, problems and promises," NASA CR-203325), National Aeronautics and Space Administration (NASA), 1995.

[127] A. K. Owen, F. K. Owen, and P. Grove, "Magnetic suspension and balance testing in support of hyper-X," in Proceedings of the 12th AIAA International Space Planes and Hypersonic Systems and Technologies, AIAA 2003-6958, Norfolk, Va, USA, December 2003.

[128] D.-K. Lee, J.-S. Lee, J.-H. Han, and Y. Kawamura, "System identification and controller design of a micro air vehicle using magnetic suspension and balance system," in Proceedings of the AIAA Guidance, Navigation and Control Conference, AIAA, August 2011. 

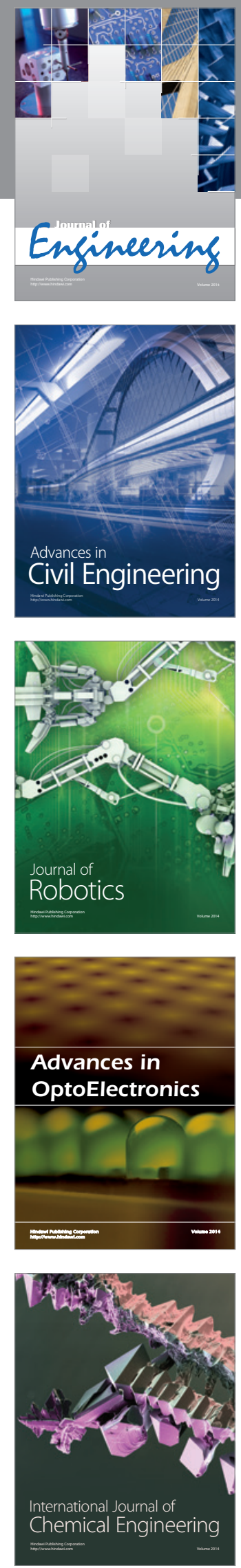

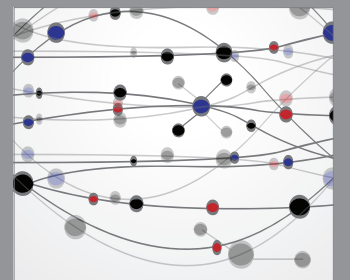

The Scientific World Journal
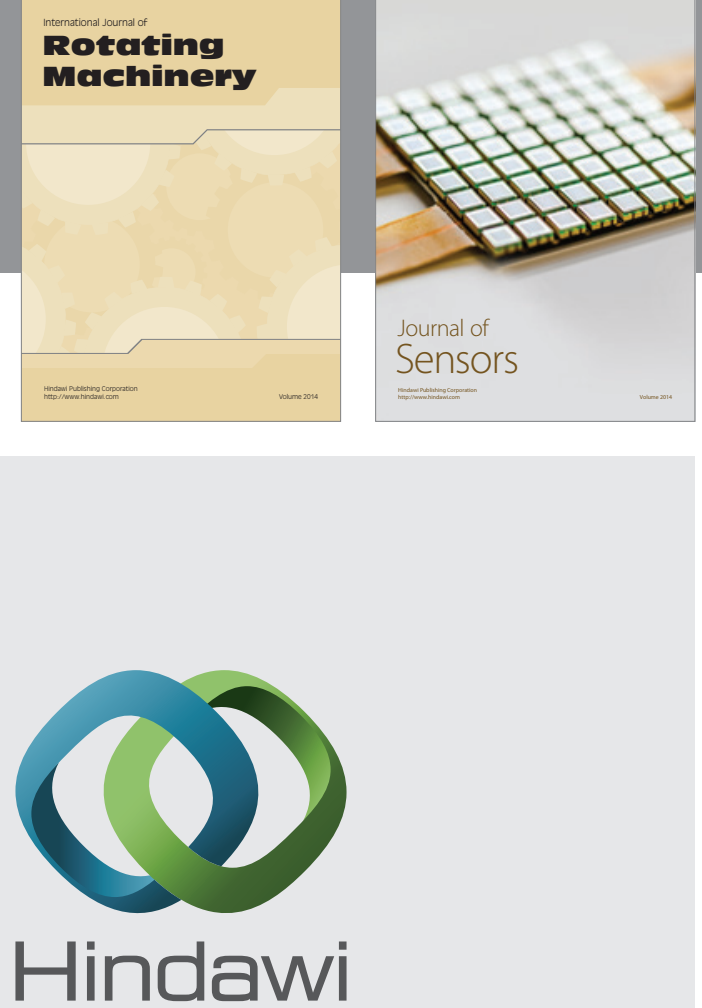

Submit your manuscripts at http://www.hindawi.com
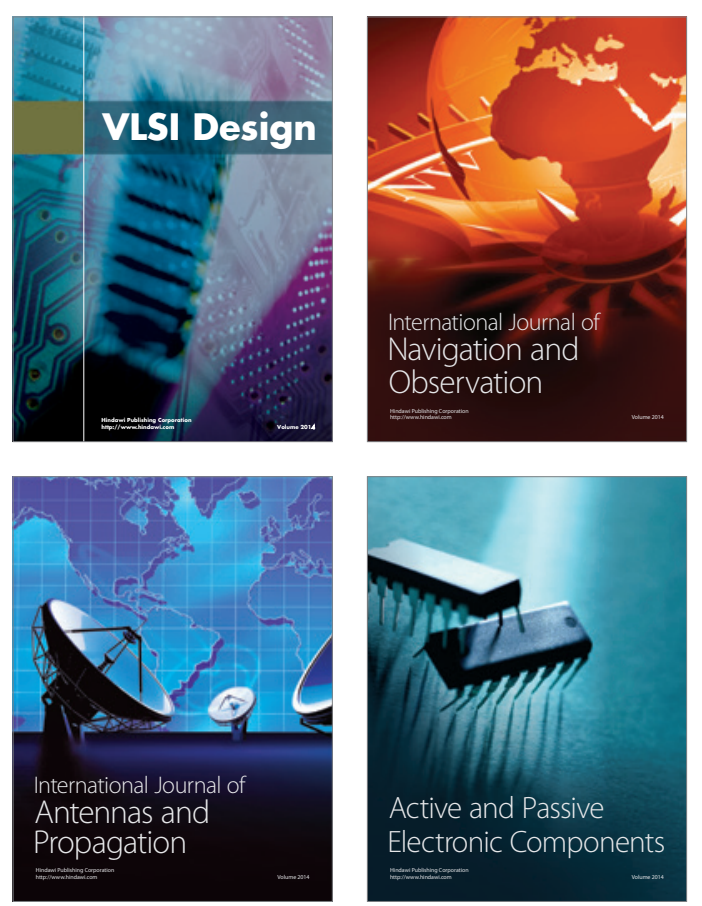
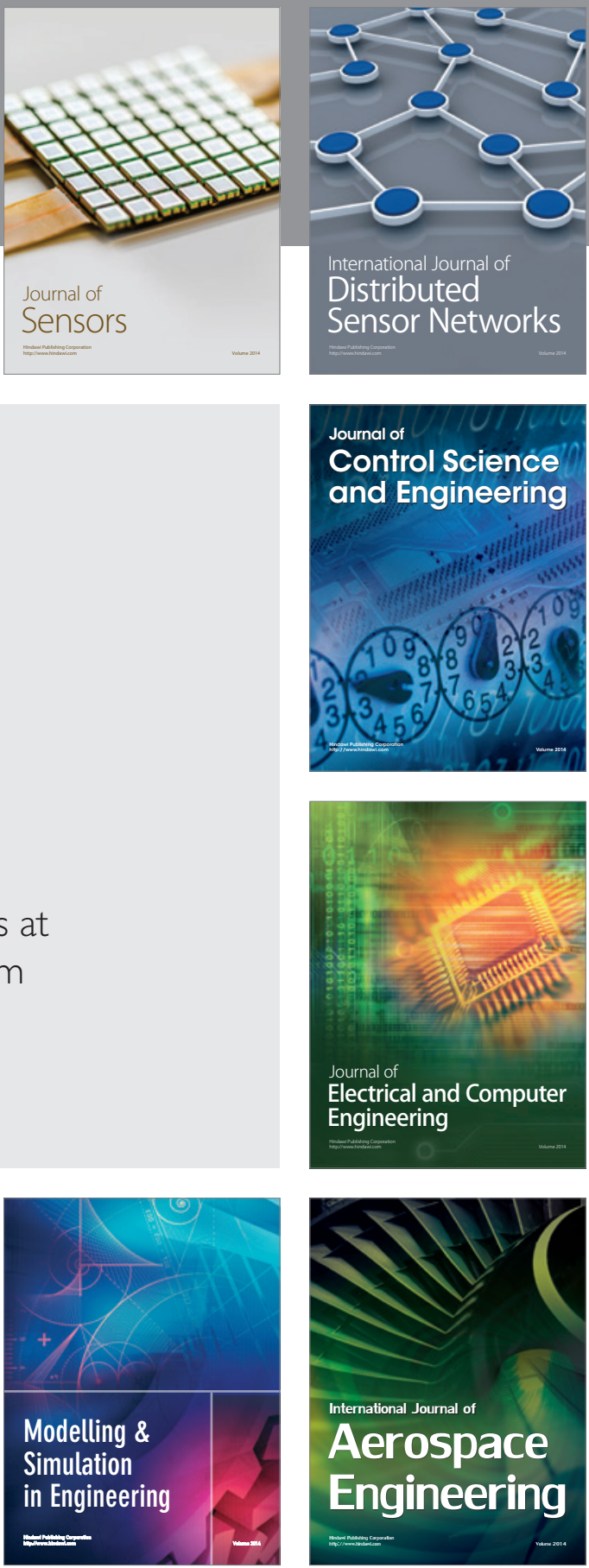

Journal of

Control Science

and Engineering
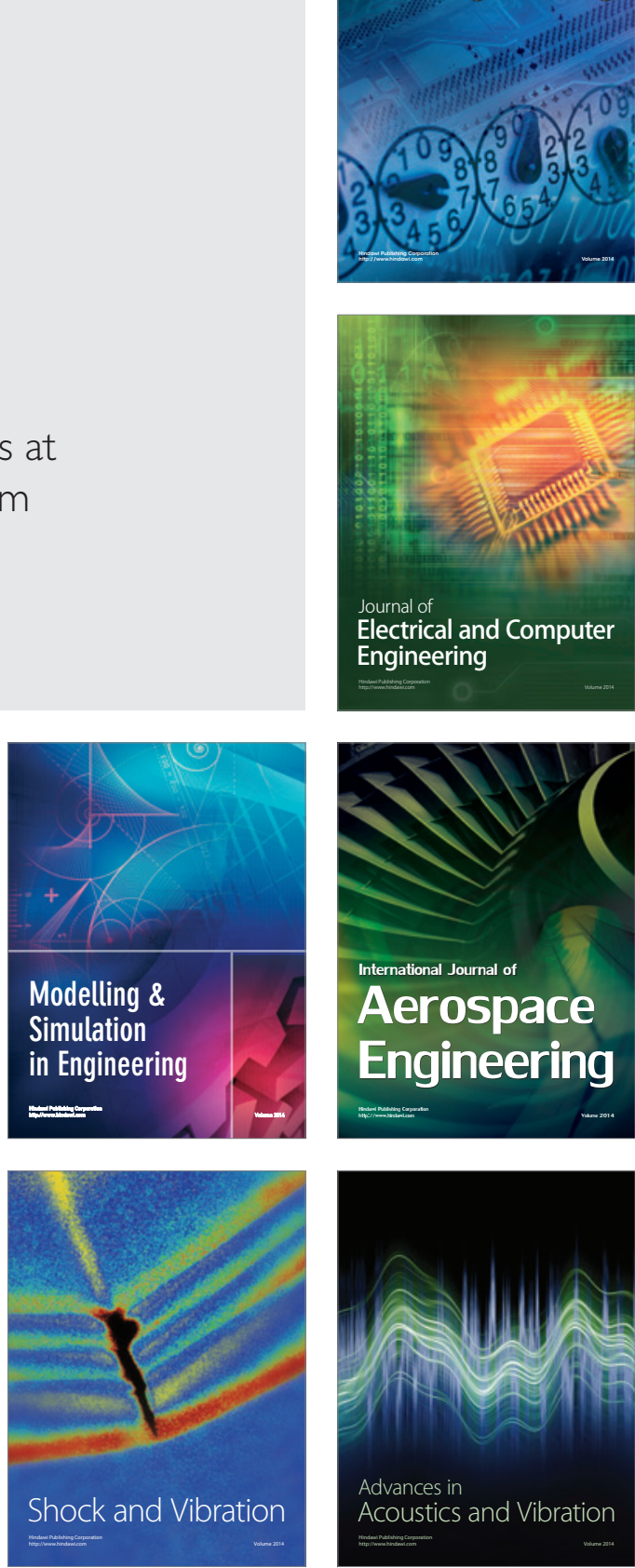